\title{
Productivity, Tradability, and the Long-Run Price Puzzle*
}

\author{
Paul Bergin \\ University of California, Davis, and NBER \\ Reuven Glick \\ Federal Reserve Bank of San Francisco
}

\author{
Alan M. Taylor \\ University of California, Davis, NBER, and CEPR
}

Draft: June 3, 2004

\begin{abstract}
Long-run cross-country price data exhibit a puzzle. Today, richer countries exhibit higher price levels than poorer countries, a stylized fact usually attributed to the "BalassaSamuelson" effect. But looking back fifty years, or more, this effect virtually disappears from the data. What is often assumed to be a universal property is actually quite specific to recent times. What might explain this historical pattern? We adopt a framework where goods are differentiated by tradability and productivity. A model with monopolistic competition, a continuum-of-goods, and endogenous tradability allows for theory and history to be consistent for a wide range of underlying productivity shocks.
\end{abstract}

JEL code: F40, F43, N10, N70

Correspondence to:

Alan M. Taylor

Department of Economics

University of California

One Shields Ave

Davis CA 95616-8578 tel: $530-752-1572$

fax: 530-752-9382

email: amtaylor@ucdavis.edu

http://www.econ.ucdavis.edu/faculty/amtaylor/

\footnotetext{
* Taylor gratefully acknowledges the support of the Chancellor's Fellowship at the University of California, Davis. We thank David Jacks, Alyson Ma, and Janine Wilson for excellent research assistance. For helpful comments we thank Stephen Broadberry, Nicholas Crafts, Robert Feenstra, Maurice Obstfeld, Mark Taylor, the NBER ITI group, and seminar participants at Claremont McKenna College, Columbia University, New York University University of California at Berkeley, University of California at Davis, University of Southern California, and the University of Texas. The views expressed below do not represent those of the Federal Reserve Bank of San Francisco or the Board of Governors of the Federal Reserve System. All errors are ours.
} 
To repeat, no one scenario can alone explain such a fact. Many different, and mutually exclusive, sufficiency conditions could lead to it. The Penn [Balassa-Samuelson] effect is an important phenomenon of actual history but not an inevitable fact of life. It can quantitatively vary and, in different times and places, trace to quite different process, as we shall see. (Samuelson 1994, 206) $^{l}$

\section{Introduction: Conventional Wisdom}

It is conventional wisdom today that richer countries have higher price levels than poorer countries. Figure 1a illustrates this idea, displaying the association of 1995 log price levels and of per capita incomes based on Penn World Table (PWT) data. That this is the consensus view is clear since similar charts appear in most textbook discussions of these phenomena (see, e.g., Krugman and Obstfeld, 2003, Figure 15.4). And although many rival theories exist to explain such an effect, there is also a broad consensus on how to explain this "stylized fact": the standard story appeals to the Balassa-Samuelson theory, based on the divergence of productivity levels in a world of traded and nontraded goods. Having languished from time to time, these ideas are now enjoying a renaissance and are being incorporated into many new open-economy macroeconomic models.

Of course, the apparent robustness of this story has proved to be of considerable relevance for many derivative conclusions in the theoretical and empirical literature. From work on sophisticated mathematical models of real exchange rates to the serious applied problem of judging differences in international living standards, the presumed correlation has had important economic and political ramifications. Since many of our PPP-based real income estimates for LDCs, past and present, often rely on extrapolations from the PWT based on this kind of relationship, and since such estimates are then used for such diverse tasks as evaluating long-run growth performance or allocating foreign aid, it is important that the patterns in the data be judged stable and predictable.

This paper raises some challenges to this comfortable consensus on the sources of covariance in international prices and incomes. The first challenge is empirical. Whilst correlations such as those seen in Figure 1a are indisputably present in today's data, one need only look back into the past to find evidence of weak or even negative correlations between national price levels and incomes per capita. After examining postwar data in great detail (and finding suggestive evidence going back several centuries) we conclude that the price-income correlation was not really very strong until the last three or four decades. This result is new and disturbing. What can explain it? This poses a second challenge to the prevailing view, and it is a theoretical challenge. We propose a new model of real exchange rates that builds on some key intuition in the Balassa-Samuelson theory, but which, by allowing for endogenous tradability, can also deliver time-varying

\footnotetext{
${ }^{1}$ A self-effacing Samuelson (1994) actually refers to the "Penn effect" in the original. This honors the laborious empirical work by the ICP/PWT team to collect the vast quantities of data that supplied the allimportant evidence, and also the robustness of the empirical finding as compared to the fragile theoretical underpinnings he exposes. With apologies to the author, we adopt the more common usage here.
} 
correlations between incomes and prices as seen in the historical data. In particular, while standard Balassa-Samuelson theory must assume that productivity gains are concentrated by coincidence in the existing traded goods sector, our model accounts for how productivity gains in the production of particular goods can in turn lead to those goods becoming traded. It therefore offers insight into how the trading pattern underlying the Balassa-Samuelson relationship can evolve over time.

\section{Stylized Facts and a Simple Model}

In theories of the real exchange rate built around tradable and nontradable goods the central stylized fact to be "explained" is the effect noted by many scholars over the years, but highlighted by Bela Balassa and Paul Samuelson in their seminal papers from the year 1964: the tendency for poorer countries to have lower overall price levels than rich countries. $^{2}$ Figure 1a shows a scatter plot of log relative price levels versus log relative income per capita for a cross section of 142 countries the year 1995 . We performed an OLS regression on these data,

$$
\ln \left(P_{i} / P_{U S}\right)=\alpha+\beta \ln \left(y_{i} / y_{U S}\right)+\varepsilon_{i}
$$

and the fitted values are shown as a straight line in the figure. ${ }^{3}$ We follow standard terminology and use the term "Balassa-Samuelson (BS) effect" as shorthand for a positive (and statistically significant) slope estimate $\beta{ }^{4}$ In our example, the slope is 0.41 with a standard error of 0.04 .

The theory that Balassa and Samuelson constructed to explain this phenomenon is also now textbook material, and the simplest version runs as follows. ${ }^{5}$ Consider two countries, home and foreign, where foreign variables are denoted with an asterisk $(*)$. Let there be two goods, traded $(T)$ and nontraded $(N)$, produced competitively in each country using only homogeneous labor as an input, with wages $W$ and $W^{*}$ in each country. Let the labor productivity in each sector be $A_{T}$ and $A_{N}$ at home, and $A_{T}^{*}$ and $A_{N}^{*}$ in the foreign country. Trade is costless for the traded goods, so their prices are equalized in the two

\footnotetext{
2In Samuelson's (1994) paper it is so central as to be labeled the "BASIC FACT" (uppercase in the original). In that paper it is also explained, as we shall see, why "explained" might belong in quotes. ${ }^{3}$ Note that in our diagrams the abscissa is measured in PPP-adjusted international dollars and so too is the independent variable in the econometrics that follow. The BS effect could, equivalently, be measured by the slope of a plot of relative prices on the ordinate versus nominal incomes converted at exchange rates on the abscissa (e.g., Balassa 1964, Figure 1). In this case, the slope would be slightly different (lower) and equal to $\beta /(1+\beta)$. This nonlinear transformation of the coefficient, naturally, should make no material difference to the analysis, but in small samples, or with noisy PPP estimates, the effect might be to blur a borderline slope, which might explain the conflicting results of Clague and Tanzi (1972) using actual versus PPP exchange rates. Officer $(1982,216)$ considers PPP-adjusted exchange rates the correct choice. ${ }^{4}$ Occasionally, more verbose terminology is invoked, viz."((Ricardo-)Harrod-) Balassa-Samuelson effect." We keep it short, but to clarify genealogy the reader is referred to the brief literature review appearing below.

${ }^{5}$ A two-factor variant with internationally mobile capital is presented by Froot and Rogoff (1995). The results are similar.
} 
countries and this pins down the relative wage levels in the two countries, since $W / A_{T}=$ $P_{T}=P_{T}^{*}=W^{*} / A_{T}^{*}$. The wage levels, in turn, pin down the nontraded goods prices with $W / A_{N}=P_{N}$ and $W^{*} / A_{N}^{*}=P_{N}^{*}$. With an arbitrary choice of numéraire, say $P_{T}^{*}=1$, one can easily solve the six equations in the six unknowns for four prices and two wage levels. Now construct a simple price index, say, Cobb-Douglas, where the share of nontraded goods in consumption is $\theta$. Then the relationship between the price levels of the two countries is given by

$$
\frac{P}{P^{*}}=\frac{P_{N}^{\theta} P_{T}^{1-\theta}}{P_{N}^{* \theta} P_{T}^{* 1-\theta}}=\left(\frac{P_{N}}{P_{N}^{*}}\right)^{\theta}=\left(\frac{A_{T} / A_{N}}{A_{T}^{*} / A_{N}^{*}}\right)^{\theta} .
$$

As is well known, neither Balassa nor Samuelson can take full credit for the discovery of this idea, though their expositions unfolded the argument at new levels of clarity and rigor. Officer $(1982,127)$ traces the lineage through Ricardo, Taussig, Ohlin, Viner, Harrod, and Rothschild. Since, 1964, however, there has been little development of the idea, perhaps owing to some of the perceived empirical weaknesses to be discussed shortly. ${ }^{6}$ A notable exception was Bhagwati (1984), who used a multi-factor setting to show that countries that were "similar" (in terms of factor abundance) might not exhibit the BS effect. ${ }^{7}$ This was one of the first papers to suggest why the BS effect might operate at certain times, or in certain samples of countries, but be absent on other occasions. ${ }^{8}$

The relevance of equation (2) for explaining the typical pattern in regression (1) depends on the assumed sources of economic growth. Though rarely tested directly, the conventional auxiliary assumption asserts that differential modern economic growth has been achieved as a result of the rapid productivity advance (in rich countries) of traded goods sectors (think: textiles, manufacturing, hi-tech). In the meantime, the nontraded goods sectors are assumed to have been relatively quiescent, and their productivities to have changed relatively little (the well worn example is the haircut). For notational convenience, let $A_{T}=a b, A_{N}=a, A_{T}^{*}=a^{*} b^{*}, A_{N}^{*}=a^{*}$. The $a$ and $a^{*}$ terms capture balanced productivity growth, which affects both sectors, and the $b$ and $b^{*}$ terms capture biased growth (or "BS growth") that only affects traded goods. Equation (2) can then be rewritten

$$
\frac{P}{P^{*}}=\left(\frac{b}{b^{*}}\right)^{\theta}
$$

\footnotetext{
${ }^{6}$ For a survey of the limited terrain see Asea and Corden (1994).

${ }^{7}$ However, the multi-factor construct comes at a "high price in loss of generality" (Samuelson 1994, 209). Samuelson devised other examples to show the fragility of the result, as noted below.

${ }^{8}$ A recent contribution is Fitzgerald (2003). We discuss this paper below, since some of aspects of her model have parallels with our own approach.
} 
This expression is independent of $a$ and $a^{*}$ because balanced productivity growth does not affect any relative prices. We can also find a simple expression for real national income, which is given by real wage income, hence

$$
\frac{W / P}{W^{*} / P^{*}}=\left(\frac{A_{T} P_{T}}{A_{T}^{*} P_{T}^{*}}\right) /\left(\frac{P_{N}}{P_{N}^{*}}\right)^{\theta}=\left(\frac{a}{a^{*}}\right)\left(\frac{b}{b^{*}}\right)^{1-\theta} .
$$

Thus, assuming fixed $a$ and $a^{*}$ but varying $b$ and $b^{*}$, the BS effect is present and the elasticity of the price level with respect to real income would be $\theta /(1-\theta)$. This elasticity will be zero when the range of nontraded goods vanishes, but is otherwise positive and can be arbitrarily large when the nontraded share approaches unity.

However, it is also clear from the above that the BS effect is not guaranteed to exist. The BS effect will be zero if the sources of growth are spread across the two sectors evenly, as when $a / a^{*}$ changes but $b / b^{*}$ does not. And, since $\theta>0$, it is only biased technological change favoring the traded sector that can generate the BS effect, and the expression is increasing in $b / b^{*}$. And there is even the possibility of an anti-BS effect: if technological change were biased toward nontraded goods (here equivalent to a rise in $b$ and a fall in $a$ such that $a b$ remains constant) then the price level could fall as a country got richer. It is this rich range of possibilities that invites empirical investigation, as the range of possible results has very different implications for how we should think of the sources of economic growth over the very long run.

\subsection{A Long-Run Price Puzzle and the Emergence of Divergence}

Returning to the long-run data, it is just as well that such a variety of outcomes can be accommodated. Figure $1 \mathrm{~b}$ shows that in the 1950 PWT data for 53 countries the BS effect was much weaker, with a slope of only 0.08 and a standard error of 0.07 . Table 1, panel (a) confirms that, in a sequence of PWT cross sections every 5 years from 1950 to 1995, the BS effect has gradually strengthened, with the slope estimate roughly quadrupling in size over half a century. In their 1964 contribution, Balassa and Samuelson were certainly very timely, if not quite ahead of their time, since the 1960 cross section supports their hypothesis, but from a statistical standpoint there was not much evidence when they wrote, and the overwhelming support in large samples has accumulated ever since.

Our evidence hints at a new stylized fact: perhaps the BS effect has not been a universal feature of modern economic development, and instead has just appeared rather suddenly in the postwar period? Is this conclusion justified, and what could explain it? Were Ricardo, Taussig, and other pioneers concerning themselves more with a theoretical possibility than a proven empirical feature of their bygone eras?

To further explore the question, Table 1(b) examines longer run historical data prior to the postwar PWT sample, and as far back as $1870 .{ }^{9}$ The obvious drawback is that

\footnotetext{
${ }^{9}$ Historical time-series studies of the BS effect are rare. One of the few is Lothian and Taylor (2003).
} 
such data, whilst longer in span, are narrower in terms of cross section coverage. One set of estimates of regression (1) is based on the real exchange rate data compiled by Taylor (2002) linked to PWT postwar price levels and compared to the real income per capita of Maddison (1995, 2001). These results also support the notion that the BS effect has only emerged and strengthened over recent decades. Before 1920 there are no significant slope coefficients at the 5\% level and occasional negative slopes. The 1920 and 1930 regressions exhibit the BS effect, but the 1950 regression does not. Again, only after 1960 are the effects consistently positive. Subject to the caveat that we have more fragile data for a smaller sample of countries, these results offer further support to our findings.

Are these longer run results robust? Aside from the small sample size, an obvious source of worry is the use of long-span deflator series. As has been noted in other contexts (De Long 1988), back-projections in Maddison data can introduce serious errors-in-variables problems. Suppose today's data were accurate, but the historical price deflators were flawed (for this example assume that all the nominal output data were correct). Then, by back projection, errors in the price level in the past would be negatively correlated with real output levels in the past, introducing an anti-BS bias into regression (1) on historical cross sections. The problem would get more severe as the errors accumulated in (backwards) time, and the illusion of a BS effect disappearing in the past would be created.

We can envisage three responses to this concern. One is that even in the postwar PWT data where data quality is thought to be better and the time separation of any cross section from a benchmark is small before 1970 - and where several benchmarks exist after 1970 - the strengthening of the BS effect is still confirmed. A second response is to go back and use true benchmark data in the distant past to avoid back-projection pitfalls. Unfortunately, the construction of historical PPP benchmarks is in its infancy and only a limited set of countries have been studied. Ward and Devereux (2003) construct true PPP benchmarks for 12 countries at 5 dates from 1872 to 1950, and correct the Maddison real income estimates accordingly. They find, puzzlingly, that the dispersion of price levels in this group of converging economies did not change much over the last 100+ years; but Table 1(b) shows that, despite this, the correlation of price levels with per capita output levels did strengthen markedly over time in this sample. Thus, the finding of a generally weak BS effect prior to 1950 is unchanged whether one uses these benchmark data (B) or the Maddison constructs (M). ${ }^{10}$ A third possible response to the errors in variables critique would be to admit that such problems could be present but are not yet verifiable. The existing Ward-Devereux benchmark data are a welcome contribution and an important advance, but we need data for a much larger number of countries. Resolving this conundrum might be a goal of future research by macroeconomic historians.

\footnotetext{
${ }^{10}$ Another important set of historical GDP estimates has been constructed but it is unsuitable for use in this paper. Prados de la Escosura (2000) corrects the Maddison data by assuming a uniform BS effect over time, back projecting the postwar relationship to provide a set of alternative deflators in the late nineteenth and early twentieth century. If employed here, such estimates would impart circularity in our argument, since they assume that the BS effect has remained consistent over time.
} 
Feeling somewhat reassured by the close alignment of the Ward-Devereux and Maddison estimates we searched for a largish historical cross section, and we finally refer the reader to the row marked 1913 where we compare Maddison's real GDP figures with nominal income figures from standard sources, to arrive at a set of $N=24$ countries with Maddison (implicit) price levels and real income per capita data. For this cross section also the BS effect is found to be statistically insignificant and even of the wrong sign. Figure 1c displays the raw data and the result is clear to the naked eye.

Finally, to push the limits of data availability, we tried to test for the BalassaSamuelson effect in data stretching back from 1850 as far as 1500. Broadberry and Gupta (2003) have assembled a database for various European cities, India, and China for this period, comprising silver wages, grain wages, and (for Europe only) cross-country consumption price levels (based on the work of Robert Allen and others). Since real income per capita data do not exist for this period, we regress their CPI level on the real wage level for 14 European cities over seven non-overlapping 50-year periods from 1500-49 to 1800-49. Table 1(c) shows that in this period there was little evidence of a BS effect, and that in most periods the slope estimate was of the wrong sign, albeit with some hint of a pro-BS trend over time. Again, we view this as prima facie evidence that the textbook BS effect that we take for granted today has not necessarily been a "universal constant" of history. This is, we propose, a significant and original finding.

We have examined the data in other ways to check the robustness of our finding. Panel estimation is feasible given that two of our data sets contain annual data: PWT after 1950 and Taylor/PWT/Maddison since 1870. Running a cross section regression on these data in every year produced the slope estimates (and 95\% confidence intervals) shown in Figures $2 \mathrm{a}$ and $2 \mathrm{c}$. (Figure $2 \mathrm{~b}$ shows that the PWT result is not an artifact of changing sample size, since the effect is just as large when we restrict attention to a balanced panel of 53 countries from 1950 to 1998). Thus, even outside the benchmark dates in Table 1, our basic story is reinforced. The PWT data show an almost monotonic upward trend in the slope estimate, and the long span data show that this up trend is essentially a postwar phenomenon.

Table 2 reports the results of panel estimation by decade on these datasets. We think some care is needed once we leave the realm of pure cross-section empirics. For one thing, identifying the BS effect from a time series correlation could be misleading, since high-frequency business-cycle correlations of the real exchange rate with output fluctuations (arising from quite different mechanisms) might cloud the picture. Panel estimation allows us to keep the cross-section features of the data intact, but only with the right choice of technique. Since the presence of the BS effect after 1950 is generally accepted, and since we wish to argue for the more novel finding that the BS effect was absent previously, it is important to adopt a panel econometric specification that does not bias against finding a BS effect.

Since the BS hypothesis is, fundamentally, a statement about cross-sections, and since we have what purport to be price level data (not just indices), we are in a position to study absolute, not relative PPP dynamics. Hence, we chose to omit country effects (fixed or random) in the intercept, since that would be tantamount to restricting the model to 
time-series identification. If we failed to find a BS effect in that setting, a skeptic could fairly claim that the fixed effects were absorbing all of the interesting parts of the BS story. Hence we estimate (1) using panel data, a common intercept, and with corrections for an error term with a common $\operatorname{AR}(1)$ term in all countries. ${ }^{11}$

Table 2 shows that the results are essentially the same in a dynamic panel setting. In Panel (a) the PWT data exhibit a steadily increasing slope that increases by a factor of 3 from 0.12 in the 1950s to 0.32 in the 1990s. Panel (b) shows that for the long span data, the BS effect is weak before 1920, of mixed import from 1920 to 1960, and strong from 1960 to the present.

If indeed the BS effect has strengthened markedly in the last 50 years, this would reconcile the mixed findings in a wider literature that has from time to time examined the BS effect and its theoretical underpinnings in postwar data. Older studies that focused on the 1950s and 1960s tended to find weak evidence, such as Officer (1982). ${ }^{12}$ More recent studies have sometimes found stronger results, but, according to a recent survey, "[o]verall, the empirical evidence on the Harrod-Balassa-Samuelson effect is quite mixed" (Sarno and Taylor 2002, 82). ${ }^{13}$

Even so, puzzles remain. In many macro studies, as well as in some micro studies, when a statistically significant slope coefficient has been found, it is not at all clear that it coincides with the model parameters according to BS logic. For example, in a study of 24 developed and developing countries in 1979, the price of a haircut was found to vary systematically with per capita income and by a factor of about 5 to 1 from poor to rich; but per capita incomes varied by a factor of about 25 to 1 ; with stagnant TFP in haircuts, the BS logic would imply that incomes (wages) and nontraded prices should move equiproportionately. ${ }^{14}$ Many such deviations from the simple theory have been pointed out in the literature.

\footnotetext{
${ }^{11}$ The estimate of the $\operatorname{AR}(1)$ parameter $\rho$ can then be read as a half-life of deviations from equilibrium real exchange rates. The estimation also allows for an error with contemporaneous cross-sectional correlation across countries (O’Connell 1997).

${ }^{12}$ Our slope coefficients can be directly compared with those of Officer (1982, Chapter 16, especially Table 2). He examined the OECD economies in successive annual cross-sections from 1950 to 1973 and found no BS effect in (1). The slope was often close to zero in the 1950s and 1960s, though rising to around 0.25 circa 1970. Our results are in broad agreement: we find that most of the BS action has arrived in the years since Officer's analysis ended, although even in the 1960s, a small effect was there, but was only detectable in a large sample that included more low income countries. Thus, Officer's weak results might be explained by a small sample ( $N=15$ at most). Alternatively, a focus on countries at similar levels of development might rob the regression of variance or introduce countervailing effects (Bhagwati 1984; Fitzgerald 2003).

${ }^{13}$ See, inter alia, Hsieh (1982); Marston (1990); Micossi and Milesi-Ferreti (1994); De Gregorio, Giovannini, and Wolf (1994); De Gregorio and Wolf (1994); Chinn and Johnston (1996); Ito, Isard, and Symansky (1999); Chinn (2000). The newer studies and their estimates are not directly comparable to ours, since they address some of the internal workings of the BS hypothesis, e.g., using manufacturing and/or services employment to attempt to pin down the underlying sectoral productivity shocks.

${ }^{14}$ Clements and Semudram (1983), based on data on the price of a shampoo and set in various cities, and drawn from a travel brochure for women published by the airline QANTAS. This is akin to today's famous Big Mac index, though the nontraded content of a haircut may be rather higher than that of a burger.
} 


\subsection{Theory versus History: Disconnect?}

The data seem to be sending a strong and consistent message. The BS effect has not always been a fact of economic life, and appears to be a phenomenon of only the postwar period. This new stylized fact raises many interesting questions: Which models can most plausibly explain such an historical pattern in the data? And what do the theory and the empirics tell us about the mechanics of economic development?

The simple model can, of course, be rigged to produce the actual historical changes seen by assuming suitable changes in exogenous variables. The question is whether such forces seem historically plausible. And because the simple model is so simple, it is also easy to question. For example, it yields a linear mapping from technologies to price levels so there is no nonlinear part of the model to complicate the predictions (this will not be true of the new model we introduce next). There are just two ways for the BS result to emerge over time. Either the biasedness of productivity growth would have to increase (more growth via $b$ than via $a$ ); or else the nontraded share $\theta$ would have to rise over time to steepen the slope for a given $b$. Doubts arise because neither of these mappings of theory into history seems entirely clean.

Consider the biasedness of technological change toward traded goods. Is this any stronger in the recent postwar period than, say, in the $19^{\text {th }}$ century or early $20^{\text {th }}$ century? Most historians seem to unanimously agree that all of the goods touched by the first Industrial Revolution were tradable - they just cannot agree on which ones. The new school stresses cotton textiles, iron, and a few other goods (Crafts 1985); the traditional school lists a broader range of goods, such as typical British products like umbrellas and beer (Temin 1997, 75). ${ }^{15}$ Both schools are beset by a seeming price paradox: if TFP surged ahead in British tradables (and later in other countries that industrialized to differing degrees) it ought to have imparted a huge BS effect, but nothing that strong is visible in the data.

Alternatively, if it is felt that the story might fit better in the recent postwar era when the BS effect has surfaced in the data, the rise of the service sector in modern, rich economies also militates against the BS logic. To the extent that modern deindustrialization in countries like the U.S. is supply and not demand driven (e.g., by changes in organization or information technology for nontraded services in rich countries, or by the transfer of traded-industrial good technologies to poor countries) the BS effect is weakened. And, to the extent that many such services are now becoming tradable, the model has even more problems in its basic assumptions.

One might also appeal to changes in the nontraded share $\theta$, but as a narrative tool this also appears blunt. Over the very long run, the only proxy we really have for $\theta$ is the

\footnotetext{
${ }^{15}$ Temin $(1997,67)$ notes out that in the Harley (1993) CGE model, the "other manufactures" were nontraded by assumption.
} 
ratio of trade to GDP, both at the national and global level. ${ }^{16}$ These data exhibit an increasing trend in the late nineteenth century, a collapse from roughly 1914 to 1945, and a recovery in the postwar period to even higher levels by the $1990 \mathrm{~s} .{ }^{17}$ On the one hand, the well-known shift to autarky in the 1920s and 1930s does line up with a marked strengthening of the BS relationship in those decades (see Table 1). And, conversely, perhaps the rise in trade shares from 1870 to 1914 weakened the BS effect in that epoch. But from 1945 to the 1990s the conventional wisdom views the world as having become more integrated over time in goods markets. This would imply a fall in $\theta$ in the simple model and a weakening of the BS effect, which is not what has happened at all, at first glance.

One possible way in which $\theta$ has increased in recent decades, however, would be in the increased range of intermediate stages of wholesaling, retail, and distribution. It is now appreciated that these activities do comprise a large share of today's economy and have important effects on real exchange rates (Obstfeld 2001; Burstein, Neves, and Rebelo 2002). Our model does not incorporate these activities, not does it incorporate intermediate stages of production that have increased some as a share of value added (GDP) but even more as a share of output and trade in a "fragmenting" world economy of vertical specialization (Feenstra 1998; Yi 2003). These forces may have expanded markedly over the last fifty to one hundred years to raise the nontraded share of total economic activity. Working in the converse direction, is also striking that the "tradedness" so measured varies a great deal between different sectors of the economy, remaining on a fairly flat trend as a ratio to GDP as a whole, but increasing as a ratio to merchandise value added (Irwin 1996; Feenstra 1998). Getting a tighter grip on these issues remains a target for future research.

Although the simple model could be tinkered with further, we think the lack of harmony between the simple model and the empirical record should be viewed as grounds for further theoretical investigation.

\section{A More General Model}

One unfortunate restriction of the simple model set out above is that there are only two goods. This means that the possible rankings of goods according to tradability and productivity are very limited. Either the traded good is more or less productive than the nontraded good; no other configuration is possible. This is a gross simplification of reality in two respects. First, many types of traded and nontraded goods exist; their productivity levels could advance at different rates and these rates need not be congruent with the degree of tradability. Second, goods are either traded or nontraded by assumption in the model but not in reality. As Meade (1951, 232; quoted by Obstfeld

\footnotetext{
${ }^{16}$ True, this is not really the right concept—in the model the share of goods traded is not the same as the share of output traded - but it appears to be the only game in town. Thus, the trade share of GDP is commonly used as a control variable in other settings with a traded-nontraded dichotomy (e.g.. see Hau 2002).

${ }^{17}$ See, for example, Findlay and O'Rourke (2003) and Estevadeordal, Frantz and Taylor (2003, Figure 1).
} 
2001) noted, "products range with almost continuous variation between those for which the cost of transport is negligibly low in relation to their value and those for which the costs of transport are so high as to be in all imaginable circumstances prohibitive."

In principle, then, if a country became relatively very successful (productive) at producing a nontraded good, it might be able to overcome transport costs barriers and export the good to foreign markets. We therefore introduce a more flexible and realistic theory. The model takes a Ricardian-like model with a continuum of goods (Dornbusch, Fischer, and Samuelson 1977) and monopolistic competition, allows for transport costs and endogenous tradability as in Bergin and Glick (2003), and develops it to explore the implications of evolving sectoral productivity distributions. ${ }^{18}$ Whereas the standard Balassa-Samuelson theory above had to assume that productivity gains are concentrated by coincidence in the traded goods sector, our model accounts for why goods experiencing productivity gains tend to become the traded goods. It seems logical that a model that can explain how Balassa-Samuelson effects can arise endogenously would provide a natural starting point for understanding why Balassa-Samuelson effects have tended to rise gradually over time.

\subsection{Model Specification}

In the model there are two countries, home and foreign (the latter denoted $*$ ), and each country's output consists of a distinct continuum of differentiated goods (labels $H$ and $F$ will be used here). ${ }^{19}$ Each country's goods are indexed on the unit interval and are produced by monopolistically competitive firms using labor as the sole input in a linear (constant returns to scale) technology. In principle, any good can be exported but there are fixed costs of exporting $f_{X}$ for any good, which are borne by the exporting firm. ${ }^{20}$ Traded goods are labeled $T$ and nontraded $N$. Agents preferences are standard CES and apply to home goods and importables. Key assumptions are that each country specializes in a range of goods that are unique to that country (albeit goods from different countries are substitutes) and that the continua of goods are exogenously given.

\footnotetext{
${ }^{18}$ In this application the focus is on relative productivities with application to the Balassa-Samuelson effect. For tractability only the simplest transport cost structure will be explored. The reader is referred to Bergin and Glick (2004) where the theory is further developed for a variety of transport cost and productivity scenarios.

${ }^{19}$ Note that by assuming different goods in each country, the LOP basis of PPP is essentially discarded This model can generalize simply to an $N$-country world with a distinct range of goods in each country. A different approach to the Ricardian model is to allow a common set of goods to be potentially produced in all countries, and then have only the lowest-cost supplier actually export the good to each market, as in the probabilistic model of Eaton and Kortum (2002). An interesting avenue for future research would be to explore the implications of endogenous tradability and the Balassa-Samuelson effect in that type of setting.

${ }^{20}$ Bergin and Glick $(2003,2004)$ consider variable (iceberg) trade costs also. The general intuition developed in this paper would generalize to this case, although the computational difficulty would, in general, be greater (for reasons to be explained later). To facilitate intuition, we study the fixed cost case where the greater range of closed form solutions obtain. It suffices to note that the model studied here does include the case of uniform iceberg costs on all traded goods. Problems arise when the iceberg cost varies by good, as noted below.
} 
Related problems are studied in a paper by Fitzgerald (2003) but her model differs in several ways. Our shipping technology has fixed (and possibly variable) costs, but hers is iceberg only. Instead, her fixed costs appear in production, leading to intra-industry trade and endogenous specialization through a scale-related mechanism à la Krugman. Her empirical sights are therefore trained, appropriately, on a restricted sample of developed countries including, especially, the EU.

Full details of the model are laid out in the Appendix, but the essential building blocks are as follows. Home and foreign agents consume CES aggregates of their own domestic goods and the other country's traded (export) goods. Let $n$ and $n{ }^{*}$ denote the (endogenous) share of nontraded goods in each country, where goods are ordered such that $[0, n]$ and $\left[0, n^{*}\right]$ are the nontraded goods. Then the top-level aggregations are

$$
\begin{aligned}
C & =\left(\left(\theta\left[n^{*}\right]\right)^{\frac{1}{\phi}}\left(C_{H}\right)^{\frac{\phi-1}{\phi}}+\left(1-\theta\left[n^{*}\right]\right)^{\frac{1}{\phi}}\left(C_{F T}\right)^{\frac{\phi-1}{\phi}}\right)^{\frac{\phi}{\phi-1}} \\
C^{*} & =\left((\theta[n])^{\frac{1}{\phi}}\left(C_{F}^{*}\right)^{\frac{\phi-1}{\phi}}+(1-\theta[n])^{\frac{1}{\phi}}\left(C_{H T}^{*}\right)^{\frac{\phi-1}{\phi}}\right)^{\frac{\phi}{\phi-1}}
\end{aligned}
$$

where $\phi>1$ is the elasticity of substitution between home and foreign goods and $\theta\left[n^{*}\right]$ is the domestic residents' own-goods bias coefficient that depends (endogenously) on the number of imported varieties. As $n^{*}$ rises and fewer varieties are imported by domestic residents, the relative weight in the consumption basket placed on home goods rises and on imported goods falls, i.e. $\theta^{\prime}>0$. The own-bias coefficient for foreign residents, $\theta[n]$, is interpreted analogously. ${ }^{21}$ The indices for domestically produced goods, and their subindices, are in turn defined by

$$
\begin{aligned}
\left(C_{H}\right)^{(\phi-1) / \phi} & =\int_{0}^{n}\left(c_{H i}\right)^{(\phi-1) / \phi} d i+\int_{n}^{1}\left(c_{H i}\right)^{(\phi-1) / \phi} d i \\
& =n\left(\frac{C_{H N}}{n}\right)^{(\phi-1) / \phi}+(1-n)\left(\frac{C_{H T}}{1-n}\right)^{(\phi-1) / \phi} \\
\left(C_{F}^{*}\right)^{(\phi-1) / \phi} & =\int_{0}^{n^{*}}\left(c_{F i}^{*}\right)^{(\phi-1) / \phi} d i+\int_{n^{*}}^{1}\left(c_{F i}^{*}\right)^{(\phi-1) / \phi} d i \\
& =n^{*}\left(\frac{C_{F N}^{*}}{n^{*}}\right)^{(\phi-1) / \phi}+\left(1-n^{*}\right)\left(\frac{C_{F T}^{*}}{1-n^{*}}\right)^{(\phi-1) / \phi}
\end{aligned}
$$

\footnotetext{
${ }^{21}$ In the appendix we show formally that the bias weights on own goods $\theta\left[n^{*}\right], \theta[n]$ depends on the mass of own goods (normalized to 1 in each country) relative to the total mass of (own plus imported) varieties available for own consumption $\left(1+1-n^{*}\right.$ in the domestic country, $1+1-n$ in the foreign country).
} 
where the elasticity of substitution among individual varieties of the home good and the foreign good is also assumed equal to $\phi$. At home, the $H N$ goods occupy $[0, n]$ and $H T$ goods $[n, 1]$; on a separate foreign interval 1 , the $F N$ goods occupy $\left[0, n^{*}\right]$ and $F T$ goods $\left[n^{*}, 1\right]$. Using duality, and noting symmetry, it is equivalent to proceed using the corresponding price indices for all of the above aggregates: $P, P^{*}, P_{H N}, P_{H T}, P_{H T}^{*}, P_{F N}^{*}$, $P_{F T}^{*}, P_{F T^{*}}$

The production side is simple. Each home firm employs $l_{H i}$ workers and pays them the wage $W$, and similarly for the foreign firms. On each interval, the output of good $i$ is given by

$$
y_{H i}=A_{i} l_{H i}, \quad y_{F i}=A_{i}^{*} l_{F i}
$$

Profit maximization by the monopolists leads to the standard cost-markup pricing. In the presence of iceberg shipping costs, pricing would differ across markets; but this is not crucial for intuition and is omitted in the simple case considered here:

$$
p_{H i}=p_{H i}^{*}=\frac{\varphi}{\varphi-1} \frac{W}{A_{i}}, \quad p_{F i}=p_{F i}^{*}=\frac{\varphi}{\varphi-1} \frac{W^{*}}{A_{i}^{*}}
$$

where $\varphi /(1-\varphi)$, the markup factor, is assumed to depend on an elasticity of substitution parameter $\varphi$ that differs from that across varieties of goods $\phi .^{22}$

The crux of the model is the distribution of productivities across goods in each country. Firms in the domestic (foreign) country have a distribution of productivity levels $F\left[A_{i}\right]\left(F\left[A_{i}^{*}\right]\right)$. Among these firms, $1-n=F\left[A_{n}\right]\left(1-n^{*}=F\left[A_{n}^{*}\right]\right)$ are exporters, who have a distribution of productivity levels $\left[A_{n}, A_{\max }\right]\left(\left[A_{n}^{*}, A_{\max }^{*}\right]\right)$ given by the conditional distribution $F\left[A_{i}\right]\left(F\left[A_{i}^{*}\right]\right)$ on these intervals. We define special (weighted) productivity averages for home goods $\tilde{A}$, nontraded home goods $\tilde{A}_{N}$, traded home goods $\tilde{A}_{T}$, and their foreign analogues

$$
\begin{array}{ll}
(\tilde{A})^{\phi-1} \equiv \int_{0}^{1} A_{i}^{\phi-1} d i, & \left(\tilde{A}^{*}\right)^{\phi-1} \equiv \int_{0}^{1}\left(A_{i}^{*}\right)^{\phi-1} d i \\
\left(\tilde{A}_{N}[n]\right)^{\phi-1} \equiv \frac{1}{n} \int_{0}^{n}\left(A_{i}\right)^{\phi-1} d i, & \left(\tilde{A}_{N}^{*}\left[n^{*}\right]\right)^{\phi-1} \equiv\left(\frac{1}{n^{*}}\right) \int_{0}^{n^{*}}\left(A_{i}^{*}\right)^{\phi-1} d i \\
\left(\tilde{A}_{T}[n]\right)^{\phi-1} \equiv\left(\frac{1}{1-n}\right) \int_{n}^{1} A_{i}^{\phi-1} d i,\left(\tilde{A}_{T}^{*}\left[n^{*}\right]\right)^{\phi-1} \equiv\left(\frac{1}{1-n^{*}}\right) \int_{n^{*}}^{1}\left(A_{i}^{*}\right)^{\phi-1} d i
\end{array}
$$

\footnotetext{
${ }^{22}$ In our simulations we assume that $\phi<\varphi$ on the presumption that the elasticity of substitution among firms in a given sector (e.g. between Honda and Toyota) is greater than that across sectors (e.g. between autos and food).
} 
While $\tilde{A}$ is independent of $n, \tilde{A}_{N}$ and $\tilde{A}_{T}$ are not. If goods are ordered with increasing productivity, then $\partial \tilde{A}_{T} / \partial n>0, \partial \tilde{A}_{N} / \partial n<0$, i.e. average productivity rises (falls) in the traded sector (nontraded) sector with increasing $n$. Intuitively, as the share of nontraded goods in the economy rises, goods at the low productivity end of the traded goods sector become nontraded, and the average level of productivity of all remaining traded goods rises. ${ }^{23}$

\subsection{Solving for Tradedness and Relative Prices}

The model solves conditionally as follows. Given $n$ and $n^{*}$, consider the set of 22 endogenous variables, consisting of $C, C_{H}, C_{H N}, C_{H T}, C_{F T}, P, P_{H}, P_{H N}, P_{H T}, P_{F T}$, and $W$, plus the foreign counterpart variables (denoted $*$ ). Production markups link prices to wages. Standard CES demand conditions link prices to consumption quantities and, thence, via technology, to derived labor demand. Market clearing (plus balanced trade) and a numéraire choice complete the solution. It is possible to derive an equilibrium for trade, given $n$ and $n^{*}$, as shown in the Appendix. But what determines these nontraded shares? On the margin, the producers of the borderline traded-nontraded good must be indifferent between home and foreign sales, and, given the fixed costs of shipping, this entails two simple extra conditions that pin down $n$ and $n *$ in equilibrium:

$$
\left(p_{H n}^{*}-\frac{W}{A_{n}}\right)\left(\frac{1}{P}\right) c_{H n}^{*}=\left(\frac{W}{P}\right) f_{X},\left(p_{F n}-\frac{W^{*}}{A_{n}^{*}}\right)\left(\frac{1}{P^{*}}\right) c_{F n}=\left(\frac{W^{*}}{P^{*}}\right) f_{X}^{*}
$$

Consider the first of these equations. The left hand size shows the real profit per unit of home good sold in the foreign market multiplied by sales volume; the right hand size is the fixed cost of exporting, where $W / P$ represents the effective real wage rate of the labor employed to cover these costs. For the borderline good $n$ the two sides are equal, and profits from export are zero. The same is true in the foreign country. Taking sales as given, the profit term (like the $A$ term) is increasing in $n$, so all goods on the interval to the left of $n$ are nontraded and all to the right are traded, confirming the maintained assumption. In this framework, endogenous tradability arises naturally, because only goods with high enough productivity are able to surmount the transport cost barrier. ${ }^{24}$

\footnotetext{
${ }^{23}$ We will show that the solution to our model can be simply expressed as a function of the weighted productivities. Setting aside the endogeneity of $n$, the relationship of our model to the basic, textbook BS model is then clear, since the model depends only on "average" productivity levels in the traded and nontraded parts of the economy each viewed as a whole. A similar result has been derived independently in another model of endogenous tradability by Melitz (2003).

${ }^{24}$ This insight has been more extensively developed in the trade and policy literature and is not well known in the macroeconomics literature. See for example, Richardson and Rindal (1996) and Bernard and Jensen (1999). For a related equilibrium analysis, see especially Helpman, Melitz, and Yeaple (2002).
} 
The equilibrium conditions can be combined to gain some analytical results and insights into the effects of productivity on the real exchange rate. As derived in the appendix, the relative national price level may be written

$$
\left(\frac{P}{P^{*}}\right)^{\phi-1}=\left(\frac{\theta\left(\frac{W / \tilde{A}}{W^{*} / \tilde{A}^{*}}\right)^{\phi-1}+(1-\theta)\left(\frac{\tilde{A}_{T}}{\tilde{A}}\right)^{\phi-1}}{\theta+(1-\theta)\left(\frac{\tilde{A}_{T}^{*}}{\tilde{A}^{*}} \cdot \frac{W / \tilde{A}}{W^{*} / \tilde{A}^{*}}\right)^{\phi-1}}\right)
$$

where the notation suppresses the dependence of $\theta, \widetilde{A}_{T}, \widetilde{A}_{T}^{*}$ on $n^{*}, n$. Observe that the domestic country experiences a real appreciation $\left(P / P^{*}\right.$ rises) in response to a ceteris paribus (i) increase in the relative cross-country domestic wage rate, adjusted by economy-wide average productivity levels $\left((W / \tilde{A}) /\left(W^{*} / \tilde{A}^{*}\right)\right)$ and (ii) an increase in home productivity biased towards tradables $\left(\tilde{A}_{T} / \tilde{A}\right) .{ }^{25}$ These are analogous to those of the standard Balassa-Samuelson model. ${ }^{26}$

In general, the reduced form response of the real exchange to productivity changes depends on the relative wage change and the endogenous adjustment of tradability of goods. Further insight can be obtained by assuming Cobb-Douglas preferences over domestic and foreign goods and that expenditure shares $\theta$ are independent of $n .{ }^{27}$ The expression for the real exchange rate is then

$$
\frac{P}{P^{*}}=\left(\frac{W}{W^{*}}\right)^{2 \theta-1}\left(\frac{A^{*}}{\tilde{A}}\right)^{\theta}\left(\frac{\tilde{A}_{T}}{\tilde{A}_{T}^{*}}\right)^{1-\theta}
$$

where the notation reflects the dependence of productivity averages on the parameters of the productivity distribution as well as the share of nontraded goods. In the case that $\theta=1 / 2$ and equal weights are placed on domestic and foreign goods, this simplifies further to

\footnotetext{
${ }^{25}$ The first result presumes own goods bias in each country : $\theta[n] \geq 1 / 2, \theta\left[n^{*}\right] \geq 1 / 2$.

${ }^{26}$ In the special case of no export costs at all: $f_{X}=f_{X}^{*}=0$, implying all goods are traded $\left(n=n^{*}=0\right)$, then $\theta=1 / 2, \tilde{A}=\tilde{A}_{T}, \tilde{A}^{*}=\tilde{A}_{T}^{*}$, so that $\left(\frac{P}{P^{*}}\right)^{\phi-1}=\left(\frac{\left(\tilde{A}^{*} / W^{*}\right)^{\phi-1}+(\tilde{A} / W)^{\phi-1}}{(\tilde{A} / W)^{\phi-1}+\left(\tilde{A}^{*} / W^{*}\right)^{\phi-1}}\right)=1$, i.e. consumption price levels
} are equalized across countries.

${ }^{27}$ Specifically, assume $P=\left(P_{H}\right)^{\theta}\left(P_{F T}\right)^{1-\theta}, C=\left(C_{H}\right)^{\theta}\left(C_{F T}\right)^{1-\theta} /\left(\theta^{\theta}(1-\theta)^{1-\theta}\right), 1>\theta>0$. 


$$
\frac{P}{P^{*}}=\left(\frac{\tilde{A}_{T}}{\tilde{A}}\right)^{1 / 2} /\left(\frac{\tilde{A}_{T}^{*}}{\tilde{A}^{*}}\right)^{1 / 2}
$$

In this case the real exchange rate is independent of relative wages since with CobbDouglas preferences each country always spends the same amount on consumption. As in the more general case, the real exchange rate appreciates if export sector productivity rises relative to the economy average, i.e., $\tilde{A}_{T} / \tilde{A}$ rises.

Simulations in the following section will provide a better sense for these results. These also allow us to draw conclusions without imposing the simplifying assumptions used above, such as Cobb-Douglas preferences. But it should also be clear how this framework allows for a more generalized approach to the Balassa-Samuelson hypothesis and its relationship to the long-run growth. Depending on the sources of growth, the shape of the $A_{i}$ and $A_{i}^{*}$ distributions could change. This, in turn, will affect the relative wages of the two countries and the range of goods traded. In the following section we analyze what kind of shocks to the technology distribution can create the stylized fact that the Balassa-Samuelson effect has grown larger over time.

\section{Simulations}

\subsection{Technology Shocks and Calibration}

To apply the model to our problem we treat technology shocks as exogenous and use different distributions of imposed shocks to simulate various patterns of sectoral productivity change. We wish to discover which types of shocks can generate price predictions consistent with the historical stylized facts and which can't. Ours is a first attempt, but the ultimate goal for such research is to place some bounds on the historical patterns of sectoral technological change, as well as on the multi-sector macroeconomic models we build to explain them. To make some progress we need to specify some hypothetical but reasonable processes governing sectoral technological change, since we cannot consider the infinite family of all possible shocks.

We consider two types of productivity shocks (each is multiplicative in levels, or additive in logs). One shock is "balanced" or uniform across all sectors, and the other is "unbalanced" or heterogeneous across sectors, favoring some sectors more than others. The former is easily specified as a level shock in logs, but the latter requires some distributional choice over sectors. We disregard the tempting choice of a normal distribution of additive shocks to log productivity across sectors at a given time, since this would imply negative productivity shocks for half the goods at any one time, implying unreasonable technological forgetfulness. Moreover, once accumulated for the very long run, such an assumption would lead to infinitesimal productivities in a set of goods approaching measure one half in the limit. This is unappealing. 
Instead, suppose that each sector $i$ receives a new draw $X_{i t}$ of its potential log productivity level at time $t$, and that the actual technology used is given by the best draw so far to date, $\max \left\{X_{i 0}, X_{i 1}, \ldots, X_{i T}\right\}$. Clearly, sectoral productivities are then nondecreasing and initial conditions can be easily specified by choosing $X_{i 0}$. It is well known that for a large family of distributions of $X_{i t}$ with power-function tails (e.g., the Pareto), the extreme-value function asymptotically approaches a Fréchet distribution. We will apply this result, assuming that "invention" (the productivity draws) happens on a micro timescale such that over the macro time-scale of decades and centuries (the frequency at which we study the BS effect) use of the Fréchet asymptotics is valid.

Thus, in our simulations, we assume that productivity can be expressed as the multiplicative combination of a component $\alpha$ which is common to all firms and a firmspecific component $a_{i}$ that follows a Fréchet distribution (in logs)

$$
A_{i}=\alpha \cdot a_{i}[\sigma], \quad A_{i}^{*}=\alpha^{*} \cdot a_{i}^{*}[\sigma]
$$

The $\alpha, \alpha^{*}>0$ parameters represent a balanced technological change spread over all goods. The $\sigma, \sigma^{*}>0$ parameters control the degree of convexity in the distribution; increases in $\sigma, \sigma^{*}$ raise productivity heterogeneity. ${ }^{28}$ Based on earlier intuition from the simple model of Section 2, we might expect uniform productivity growth from changes in $\alpha$ not to generate BS effects, but tilting the distribution (through changes in $\sigma$ ) could well generate BS effects.

Given that it is difficult to derive full results analytically with the Fréchet distribution, the model is solved numerically for particular parameter values. To maintain simplicity, consider a case where there are ten distinct sectors in the economy. This may be viewed as a discrete approximation to the analytical model of a continuum of goods presented in the preceding section. The elasticity of substitution between individual varieties within a sector, $\varphi$, is calibrated at 6 , a common value in the literature, as it implies a reasonable markup of price over marginal cost. We set the elasticity of substitution between sectors, $\phi$, at the lower value of 2 , since it is reasonable to assume that it is easier to substitute across varieties within the same type of good, than to substitute one type of good for another. Separating these two elasticities is very useful in generating large Balassa-Samuelson effects on the real exchange rate without violating data regarding the size of price markups, and we recommend this strategy to future researchers. The fixed cost parameter, $f_{X}$, will be calibrated in each experiment to assure that half of the sectors are traded in the initial distribution.

The experiments here will consider two countries starting off at the same technology distribution, but where one country grows in productivity over the course of a century until it reaches a GDP level twice that of the poorer country. In the recent data

\footnotetext{
${ }^{28}$ Bergin and Glick (2004) show that including good-specific iceberg shipping costs introduces similar terms to these in the markup calculation, but that the derivation of equilibrium is analogous once export goods' productivities are adjusted for the iceberg loss.
} 
researchers find convincing evidence that the Great Divergence stems in large part from changes in TFP levels (Hall and Jones 1999). TFP has surged in rich countries but very little trickles down to poorer countries, and hardly any new innovative activity takes place outside the rich world (Sachs 2001). For our simulations, this may make our assumption of ceteris paribus in the foreign (poor) country a reasonable gross approximation for the long-run experience in rich and poor economies.

The productivity gain in the rich country may take one of several different forms. The heterogeneous component of productivity $a_{i}$ is assumed to follow a Fréchet distribution in logs with CDF function:

$$
F\left[\ln \left(a_{i}\right)\right]=i=\exp \left[-T\left(\frac{\sigma}{\ln \left(a_{i}\right)}\right)^{\lambda}\right]
$$

$T$ indicates the number of years over which the heterogeneous shocks have been accumulated, $\sigma$ can be interpreted as the variance of the underlying shock each year, (here set at 0.01 ), and $\lambda$ indicates the fatness of this distribution's tail (here set at unity). ${ }^{29} T$ will be parameterized as

$$
T=\mu_{T 0}+\mu_{T 1} t, \quad t=0 \ldots 100
$$

where $t$ is the number of periods of the experiment, $\mu_{T 1}$ is a scale parameter that will be calibrated to generate the desired doubling of income over the 100 year period of the experiment, and $\mu_{T 0}$ enters to permit some initial heterogeneity when the experiment specifies it. Mechanically, the $a_{i}$ part of technology is determined in log form by the inverse $\mathrm{CDF}$ of this Fréchet distribution

$$
a_{i}=\exp \left[\sigma\left(\mu_{T 0}+\mu_{T 1} t\right)^{\frac{1}{\lambda}}(-\ln (i))^{\frac{-1}{\lambda}}\right] .
$$

Since a discrete approximation of the Fréchet distribution is used here for the ten sectors, $i$ takes the value of one of the ten percentiles $(0.05,0.15,0.25, \ldots, 0.95)$.

The homogeneous component of productivity is specified

$$
\alpha=\exp \left[\mu_{\alpha 0}+\mu_{\alpha 1} t\right], \quad t=0 \ldots 100
$$

\footnotetext{
${ }^{29}$ A value of $\lambda=1$ implies a very high degree of heterogeneity, which turns out to be necessary here for generating large Balassa-Samuelson effects. Given that we take a discrete approximation of the Fréchet distribution for our 10 sectors, the highest draw for the distribution will be at the $95^{\text {th }}$ percentile, so we miss the high values at the limit of the distribution which could otherwise make moments of the full continuous distribution be infinite.
} 
where $t$ again represents the number of years of the experiment, the scale parameter $\mu_{\alpha 1}$ is set to replicate the doubling of relative productivity and income over the 100 year period, and $\mu_{\alpha 0}$ permits a time-invariant level shift when the experiment specifies it.

\subsection{Experiments and Results}

Experiment 1: Homogeneous shock. The first experiment is to consider a simple rise in the level of technology for all firms in the form of a homogeneous multiplicative shock, $\alpha$, without any heterogeneity across sectors. Suppose both countries start off with all sector productivities constant at the value of unity. ${ }^{30}$ Then let $t$ rise from 0 to 100 , with the scale factor $\mu_{\alpha 1}$ set to 0.015 , so that output in the rich country relative to the poor doubles by the end of the period. The passage of time affects neither the technology in the foreign country nor the homogeneous or heterogeneous components of productivity in the home country, so all scale factors in the foreign country and all other scale factors in the home country are set to zero. Figure 3 a shows the technology distributions of each country. Note that for home relative output to double its relative technology level must more than double, due to the fact that the foreign country benefits from the rise in home productivity.

Table 3 and Figure $3 \mathrm{~b}$ show that the effect on the real exchange rate is negative. The table reports the number of years $(t)$, the relative income and relative price levels, as well as their ratio in $\operatorname{logs}$, and the number of sectors being traded internationally from the home and foreign countries respectively. A conclusion is that by no means is it inevitable that a rise in a country's productivity generates a positive Balassa-Samuelson effect. One can see from Figure 3 that a fair portion of the overall productivity gain is located in the nontraded goods sector, which the analytics in Section 3 demonstrated would tend to produce a negative effect on the real exchange rate. This differs from the standard textbook version of Balassa Samuelson, where a balanced growth leads to a zero effect on the real exchange rate. But, in a model of monopolistic competition, price is set as a markup over marginal cost, so a rise in technology that lowers marginal costs of production will tend to lower prices and make the real exchange rate depreciate. While the possibility of a negative Balassa-Samuelson effect is of potential interest, we clearly fail to replicate the stylized fact, since the Balassa-Samuelson coefficient here never rises to positive values.

Table 3 shows that a homogeneous productivity shock also affects the trade pattern. In particular, the number of domestic sectors involved in trading falls from 5 to 3 . This is due mainly to the fact that the rise in home productivity raises the domestic wage, which raises the effective fixed cost of trading internationally. The exit of some firms from the export market means that trading becomes concentrated in fewer sectors. One

\footnotetext{
${ }^{30} \mathrm{~A}$ fixed cost of $f_{X}=0.12$ is sufficient to ensure that half of the sectors are traded. There is no need to identify the particular ordering of the ten sectors and which five of them will be traded. But once five sectors are exporting the foreign market, the price of home goods in the foreign market falls to the point that it is not profitable for a sixth set of home producers to enter. The situation for foreign exporters to the home market is symmetric.
} 
should note that the fall in the number of exporting firms is by no means synonymous with a fall in the amount of trade; in fact, the value and volume of total home exports to the foreign country rise under this experiment.

Experiment 2: Heterogeneous shock. The second experiment is to consider a shock heterogeneous by sector according to the Fréchet distribution. The scale parameter $\mu_{T 1}$ is set to 0.165 , so that output in the rich country relative to the poor doubles after 100 years, with all other scale-factor variables set to zero. Figure 4a shows the change in technology distribution, which is strongly tilted. Since this end will be turn out to be traded goods, one would expect a strong positive Balassa-Samuelson effect on real exchange rates.

Table 4 and Figure $4 \mathrm{~b}$ confirm this intuition. Note that since the BalassaSamuelson coefficient was defined as the ratio of the log of relative price to the log of relative output, it can be read from the figures as the slope of the line segment from the origin. However, the Balassa-Samuelson effect does not grow over time as productivity progressively accumulates; rather the effect on the exchange rate is large from the very beginning. The explanation lies in the fact that the trade pattern is endogenously determined. Whichever goods happen to receive the productivity gains will be the goods that can cover the fixed cost of exporting and generate profits by trading in the foreign market. So it is automatic that the heterogeneous productivity gains are concentrated in the traded goods sector. As soon as productivity differences emerge between sectors, the trade pattern adjusts to this, and the pre-condition for Balassa Samuelson is satisfied. So Balassa-Samuelson effects naturally are large even early on in the process of technological accumulation here, rather than growing over time as technology continues to accumulate. Once again the result fails to replicate the dynamics of the stylized fact.

Experiment 3: Homogeneous shock, with initial heterogeneity. As a third experiment, consider a homogeneous shock where the initial distribution of technology is not flat as assumed in experiment 1, but instead follows some Fréchet distribution. In particular, assume that the initial distribution in each country is the same as the terminal distribution in the previous experiment (so that $\mu_{T 0}$ and its foreign analogue $\mu_{T 0}^{*}$ are set so that each equals 100 (years) times the scale-factor $\mu_{T 1}$ from the previous experiment). Then allow a multiplicative shock homogeneous among home sectors, sufficient so that home relative output doubles over the 100 year experiment $\left(\mu_{\alpha 1}=0.015\right)$. Figure 5a shows this distribution, and Table 5 and Figure $5 \mathrm{~b}$ show the implication there is a strong positive Balassa-Samuelson effect.

This result is noteworthy as it suggests that a homogeneous multiplicative shock can imply negative real exchange rate effects under one set of balanced initial conditions, but positive effects under other initial conditions that involve heterogeneity. We find that this result is driven by endogenous tradability, one of the key assumptions of our model that differentiate it from the standard model. In fact, when we force the traded sectors to remain exogenously constant, this result disappears. 
To understand the combined role of endogenous tradability and heterogeneity in productivity, observe from Table 5 that the homogeneous productivity shock induces some home firms to exit the export market, just as in Experiment 1. Moreover, the degree of exit is nearly the same as seen for Experiment 1 (see Table 4) when there is no initial heterogeneity, for essentially the same reason as given previously: higher wages raise the effective fixed costs of exporting. However, the exit has an additional implication when there is heterogeneity in productivity among firms. Because the exiting firms have lower productivity than the remaining exporters, the average productivity among the remaining exporters rises. Consequently, as seen in the analytical expression (10) for relative prices, a rise in the average level of productivity of traders compared to the general average over all goods leads to a rise in the relative price level and a positive Balassa-Samuelson effect. However, although this finding provides another means of generating positive Balassa-Samuelson effects, these effects are once again large from the beginning of the process of technology accumulation rather than growing over time, so this experiment again does not replicate the stylized fact we are after. ${ }^{31}$

While none of the three cases above replicates the stylized fact of a progressively emerging and growing Balassa-Samuelson effect, the necessary ingredients for this result are present separately in the various simulations, as demonstrated in the following experiment.

Experiment 4: Homogeneous shock, followed by heterogeneous shock. Consider a rise in technology that starts off as a homogeneous multiplicative shock from an initially flat distribution, and then becomes a heterogeneous Fréchet shock. In particular, suppose a starting point where the homogeneous shock lasts for ten years, which should lead to a negative effect on the real exchange rate. Then allow 100 years of heterogeneous productivity to accumulate by the Fréchet distribution, where its positive effect on the real exchange rate works against and eventually dominates over the initial negative effect. Figure 6 a shows this distribution, and Table 6 and Figure $6 \mathrm{~b}$ show that indeed the Balassa-Samuelson coefficient grows over time from a low to high level. This cocktail of technology shocks illustrates one potential method for replicating the stylized fact.

This method for replicating the stylized fact shows that the emergence of a BalassaSamuelson effect could be contrived from mixing several explanatory ingredients to make just the right cocktail over time: a dash of homogeneity here, followed by a twist of heterogeneity there. Is there a reason to believe that the nature of the technology shock changed after some initial period of industrial revolution? Perhaps. But we have very

\footnotetext{
${ }^{31}$ Ghironi and Melitz (2003) apply a multiplicative aggregate shock of this type. Our result suggests that heterogeneity in the underlying distribution prior to their shock may be an important source for their endogenous Balassa-Samuelson result. It is also true that their impulse responses imply an initially negative Balassa-Samuelson effect which later becomes positive. However, they analyze only small shocks in a linearized model; it would not be accurate to extrapolate their result to large changes in productivity as that in the stylized fact analyzed here.
} 
little evidence here to guide us (but see below). Some might consider a more appealing story to be one that generates the stylized fact with a single continuous shock process operating on a given set of initial conditions for productivity. We propose two such processes here.

\section{Experiment 5: Productivity process that is a mix of heterogeneous and homogeneous} shocks. This process generates a delayed Balassa-Samuelson effect that contains a mix of heterogeneous and homogeneous shocks in every period; with a sufficiently large homogeneous shock component this process would be expected to generate anti-BalassaSamuelson price effects at the beginning, as in Experiment 1, but then, as heterogeneity increases over time, to generate pro-Balassa-Samuelson price effects later on, as in Experiment 3. Thus, unlike Experiment 4, we do not make a convenient cocktail with one type of shock followed by the other, but instead allow both shocks to be present in all periods. Specifically we choose to sum the two shocks with a weight of 0.3 on the previously-used homogeneous shock and 0.9 on the previously-used heterogeneous shock.

These weights cause the income per capita of the rich country to grow by a factor of 2.25 relative to the poor country in our simulation. Figure 7 a shows the productivity distribution. Table 7 and figure $7 \mathrm{~b}$ show that the effects on the real exchange rate coincide with the intuition above and indeed replicate the basic dynamics of the stylized fact - at first the Balassa-Samuelson effect is negative, but after a certain point in the divergence process the pro-Balassa-Samuelson effects kick in.

This last experiment is attractive a priori since we have little reason to believe that actual sectoral growth patterns have been characterized by either pure homogeneity or by a pure heterogeneous process like the Fréchet. But there is another alternative approach, one that arises quite naturally from a model of endogenous tradability like the one here. In particular, to generate a Balassa-Samuelson effect that is small or negative to begin with and then becomes positive, this shock should initially impact mainly nontraded goods and then later benefit mainly traded goods. If the productivity shock is concentrated on goods with initially low productivity, which thereby tend to be nontraded, the endogenous nature of the trade pattern indicates that eventually productivity will rise enough so that these goods can pay the fixed cost of trade, and they will become traded goods. This would still not allow the shock itself to change over time, but would allow the shock to continue to impact the same goods in a distinct subset of goods-yet allowing the status of the goods to change endogenously. The natural way to think of the subset of goods is as the formerly unknown (or low productivity) "emerging sectors" or "leading sectors" of a new "industrial" era of growth. We present a final experiment to illustrate this idea.

Experiment 6: Heterogeneous shocks to emerging sectors only. Assume the ten sectors are grouped into two equally-sized groups. Suppose sectors 6-10 have as an initial distribution the Fréchet that is the terminal distribution from our second experiment, and they remain static at this level. Suppose sectors 1-5 all start off at the minimum level of 
productivity, unity, and that it is these goods that are subject to the heterogeneous shocks that accumulate over the next century according to a Fréchet distribution, such that their overall home output relative to foreign doubles. An interpretation might be that the first group (sectors 6-10) is a set of "mature", non-industrial sectors that have reached their terminal technological distribution prior to the industrial revolution, whereas the second group (sectors 1-5) is a set of new "emerging industries", which have low productivity when they first emerge, but benefit from the technological improvements of the industrial revolution. ${ }^{32}$

Figure $8 \mathrm{a}$ shows the productivity distribution. Table 8 and figure $8 \mathrm{~b}$ show that the effects on the real exchange rate coincide with the intuition above and indeed replicate the basic dynamics of the stylized fact. As the country grows richer, the real exchange rate is small or negative to start, and then grows to a positive value of around 0.5 over time. There may well be yet other methods of generating this stylized fact, but this method is appealing in that it uses the endogenous determination of the trade pattern emphasized in our model to our advantage, to endogenously alter the impact of the single shock process to have a nonlinear effect on macroeconomic aggregates.

These experiments offer a number of intriguing conclusions. First, if the trade pattern truly is endogenously determined, this would tend to make the Balassa-Samuelson effect much more likely to arise. If the pre-condition for Balassa-Samuelson is that productivity shocks hit traded goods, then if the goods that can pay the fixed cost and become traded are those that receive productivity shocks, then one should expect to see BalassaSamuelson arising endogenously as a natural condition, rather than relying upon the precondition to be satisfied by mere coincidence.

But the second conclusion is that it may take time for the trade pattern to re-orient itself so that the Balassa-Samuelson pre-condition is satisfied. Since the data indicate that it did indeed take time for the effect to emerge, this suggests that productivity shocks may well have been concentrated mainly on nontraded goods initially and they became traded goods over time. In a sense, then, the precondition of Balassa-Samuelson theory is turned on its head. An interpretation is that the productivity shocks associated with the industrial revolution systematically affected new emerging sectors, which started off with low productivity and were not generally traded; as these new sectors benefited from the evolving industrial technology, it became profitable to trade them and they gradually became important traded goods.

\footnotetext{
${ }^{32}$ Mechanically, this experiment means specifying the full set of distribution parameters for both groups. We set $\mu_{T 0}=\mu_{T 0}^{*}$ for the mature group so that it equals 100 years times the value of $\mu_{T 1}$ from experiment 2 , and set all scale factors equal to zero for this group. For the emerging group, we set $\mu_{T 0}$ equal to zero, but set the scale factor $\mu_{T 1}$ so that overall home relative income doubles over the 100 year experiment.
} 


\section{Theory versus History: Reconnect?}

This paper has investigated the empirical basis of, and theoretical rationale for, the venerable Balassa-Samuelson effect over the very long run. Two big surprises appear in the data. First, the weak and uneven nature of the BS effect in the distant past; second, the marked strengthening of this effect in the last fifty years. Given the paucity of historical data, the former claim is more conjectural, yet the two findings are quite of a piece, and the latter observation alone requires new thinking, with implications for international economists, macroeconomists, and economic historians.

Our model supplies a set of tools for thinking about these results and we think it will be of interest to theoreticians in various fields. International economists will find here a new application of endogenous tradability that is complementary to several new directions in the literature (Betts and Kehoe 2003; Fitzgerald 2003; Ghironi and Melitz 2003). Macroeconomists interested in long-run growth in more then one sector will discover not only an important set of stylized facts but also some conjectures on how these should be modeled in terms of sectoral growth behavior. The paper also challenges the simplest two-sector view of most "industrial revolution" models where the two sectors are labeled "manufacturing" and "agriculture" and both are traded goods. ${ }^{33}$ Such models have been criticized for their poor match with the British historical patterns (Clark 2002; Voth 2003), not least because the assumed divergence in productivity between manufacturing and agriculture is not clear in the data. ${ }^{34}$ Lacking a nontraded sector such models obviously cannot match the patterns in the data studied here.

The results of the paper are also of importance to empirical macroeconomists and economic historians concerned with understanding the mechanisms of modern economic growth. What are our key findings? Looking first at the $19^{\text {th }}$ century there is heated debate about the sectoral gains in productivity. The extant data apply to few sectors, and treat almost half of the economy as a residual. The best efforts to date appear in Table 9 and Figure 9. T. S. Ashton summed up the Industrial Revolution as a "wave of gadgets" and ever since "traditionalists" like Landes, McCloskey, and Temin have taken this to mean a broad productivity advance across many sectors. This view has been criticized by "revisionists" such as Harley, Crafts, and Clark whose downward revisions of economywide TFP have squeezed the TFP in the residual "other manufacturing" category down to zero.

We found weak BS effects in the data so, based on the traditional BS model, this appears to be good news for the traditional school, where, if the Industrial Revolution is

\footnotetext{
${ }^{33}$ This literature is growing rapidly. Notable contributions include Lucas (1988, 2002), Matsuyama (1992), Jones (1999), Galor and Weil (2000), Hansen and Prescott (2002), and Galor and Mountford (2003).

${ }^{34}$ For example, Crafts $(1985,87)$ noted that even as early as 1840 there was no apparent gap between industrial and agricultural productivity levels. Moreover, according to Crafts and Harley (1993), and in contrast to the seminal work of McCloskey (1981), agricultural TFP growth exceeded that in all manufacturing sectors save for a select few leading sectors-Cotton, Worsteds, Woolens, Irons, Canals and railroads, and Shipping. This created the "paradox" noted by Williamson (1987) and Temin (1997) that, under the Crafts-Harley view of the Industrial Revolution, Britain had a comparative disadvantage in most of the manufacturing sector. This debate is hardly settled (Harley and Crafts 2000; Temin 2000).
} 
broad, one gets a weak BS effect. Our model supplies a very different perspective, however. Suppose the pre-industrial equilibrium featured advances in a range of "old" goods that had reached an advanced level of technology; suppose then that modern economic unleashed productivity change across a different set of goods. As our simulations show, the shift in sectoral productivity would entail an endogenous shift in trade patterns that could take many decades to work itself out. In the interim, productivity shocks would be hitting both traded and nontraded goods, muting the BS effect in the transition. We conjecture that some such forces were at work in the $19^{\text {th }}$ and early $20^{\text {th }}$ centuries, keeping the BS in check as the data show. ${ }^{35}$

By the late $20^{\text {th }}$ century the story could be quite different. By then the evolution of the international economic order-the division of the world into exporters of manufactures and exporters of primary products—had reached a crescendo (Lewis 1978). A new trade pattern became well established, and our model suggests that, under these conditions, sustained heterogeneous productivity shocks (even with some uniform shocks) would eventually show through and deliver strong pro-BS effects in the data.

At the sectoral level, research by Jorgenson and Stiroh (2000) shows that TFP has been far from uniform across industries, and the latest figures for the postwar period show a marked clustering of high growth rates in a small subset of sectors (which includes agriculture), as indicated in Table 10 and Figure 10. Moreover, there is no clear correlation in this list between the ex ante traded goods and high productivity, as our argument would suggest. In the early $20^{\text {th }}$ century the U.S. exported in petroleum, lumber, and motor vehicles, but these come in low on the list. Hi-tech goods exported today, like equipment and instruments initially appeared at the bottom of the list. This is, we think, prima facie evidence for our argument that tradability can arise (or disappear) endogenously and, with it, the BS effect.

We also find some quantity evidence that is consistent with our conjectures. It appears that the rise in productivity levels at the sectoral level has been strongly correlated in both epochs with increased exports, a key prediction of our Ricardian style model. In the $19^{\text {th }}$ century, the British industrial revolution began in textiles and soon these goods were being exported in vast quantities to the rest of the world. Temin (1997) argues that this implication extends to an even wider range of manufactures. In the postwar period for the U.S. we can examine more detailed sectoral level data at the 2, 3 and 4 digit SIC level and see a very strong correlation between log exports and log productivity (measured as value added per worker) as seen in Figure 10.

However, we hesitate to speculate further on the many ways in which our model could help explain very long-run macroeconomic history. It may seem, already, that we have succumbed to the vices of which Samuelson $(1994,205)$ warned:

\footnotetext{
${ }^{35}$ One of the mechanisms that mutes the BS effect in our model is a strong terms of trade effect that is missing in the standard two-sector BS model. Regarding the terms of trade effects, Harley $(1982,1993)$ and Clark (2003) argue that this is precisely what happened: most of the efficiency gains of the cotton textile revolution were exported to the rest of the world.
} 
Much of what Ricardo, Harrod, Balassa, or Samuelson say boils down to repetition of the brute fact of the Penn effect. Some of what is said, however, consists of specifying sufficient scenarios to create a Penn effect, along with explicit or implicit contention that these sufficient conditions have themselves been correct brute facts about economic history and geography.... My own researches, published and unpublished, re-emphasize that sufficient conditions need not be necessary...Interesting conditions that are both necessary and sufficient, alas, are too unspecific to be much more than reiterated descriptions. As I shall show, sufficient scenarios abound that can entail anti-Penn effects. The Penn effect is important, but it is not an inevitable truth of economic history. True effects can deviate from stipulated approximations in different directions and in degree that various exogenously and endogenously from case to case and epoch to epoch. (Samuelson 1994, 205)

Indeed. Theory has its limits. Key debates about the past and present are usually resolved only with great empirical brute force, not just with pen and paper. Explaining the rise of the Penn effect is no different.

Suitably chastened we offer our analysis not to extend the universe of theoretical possibilities for its own sake, but rather, we hope, to point to profitable directions in which theory and empirics can better serve each other in untangling puzzles both historical and contemporary. 


\section{Appendix}

Consider a model of two countries, home and foreign, in which each country specializes in production of distinct varieties of a differentiated good. In each country there is a separate continuum of firms each producing a different variety of the local differentiated good, denoted by $H$ and $F$, respectively. All goods produced in each country have the potential to be exported, but some endogenously determined fraction will be nontraded in equilibrium. Residents of each country consume a different basket of domestic and traded foreign varieties depending on which varieties are traded. Quantities and prevailing prices for the goods varieties consumed in the foreign country are denoted by *.

\section{Consumption}

The continuum of goods produced in each country is indexed by $i$ on the interval $[0,1] .{ }^{36}$ Let $n$ and $n^{*}$ denote the (endogenous) share of these in each country that are nontraded, where goods are ordered such that $i \in[0, n],\left[0, n^{*}\right]$ are nontraded and $i \in[n, 1],\left[n^{*}, 1\right]$ are traded in the home and foreign country, respectively. Residents in each country consume a basket of locallyproduced goods and tradable goods imported from the other country. With the total mass of goods produced in each country normalized to $1,1-n$ and $1-n^{*}$ also represent the number of goods in each country that are traded. Consequently, the total mass of varieties of goods available for consumption in the home country is the sum of the mass of domestic varieties and of the goods exported by the foreign country, i.e. $1+\left(1-n^{*}\right)=2-n^{*}$; analogously, the total mass of goods available in the foreign country is $2-n$.

Accordingly, aggregate consumption by domestic and foreign residents, $C, C^{*}$, respectively, can be defined as a CES aggregate of consumption of each country's own goods $\left(C_{H}, C_{F}^{*}\right)$ and imports of the other country's traded (export) goods $\left(C_{F T}, C_{H T}^{*}\right)$ :

$$
\begin{aligned}
& C=\left(\left(\theta\left[n^{*}\right]\right)^{\frac{1}{\phi}}\left(C_{H}\right)^{\frac{\phi-1}{\phi}}+\left(1-\theta\left[n^{*}\right]\right)^{\frac{1}{\phi}}\left(C_{F T}\right)^{\frac{\phi-1}{\phi}}\right)^{\frac{\phi}{\phi-1}} \\
& C^{*}=\left((\theta[n])^{\frac{1}{\phi}}\left(C_{F}^{*}\right)^{\frac{\phi-1}{\phi}}+(1-\theta[n])^{\frac{1}{\phi}}\left(C_{H T}^{*}\right)^{\frac{\phi-1}{\phi}}\right)^{\frac{\phi}{\phi-1}}
\end{aligned}
$$

where $\phi>1$ is the elasticity of substitution between all varieties, whether domestic or foreign in origin; and $\theta\left[n^{*}\right], \theta[n]$ are own-goods bias coefficients that depend (endogenously) on the

\footnotetext{
${ }^{36}$ Note that, although each country produces a distinct set of goods, in our notation we use the same index $i$ to order goods along each continuum.
} 
number of varieties produced locally relative to the total number of varieties available in each country: ${ }^{37}$

$$
\begin{aligned}
& \theta\left[n^{*}\right] \equiv \frac{1}{2-n^{*}}, \quad 1-\theta\left[n^{*}\right] \equiv \frac{1-n^{*}}{2-n^{*}}, \quad 0 \leq \theta\left[n^{*}\right] \leq 1 \\
& \theta[n] \equiv \frac{1}{2-n}, \quad 1-\theta[n] \equiv \frac{1-n}{2-n}, \quad 0 \leq \theta[n] \leq 1
\end{aligned}
$$

Observe that if $n=n^{*}=0$ and all home and foreign varieties are traded, then there is no goods bias, i.e. $\theta[n]=\theta\left[n^{*}\right]=1 / 2$. As $n, n^{*}$ rise and fewer varieties are imported by each country, the relative weight placed on own goods rises and on imported goods falls, i.e. $\theta^{\prime}>0 .^{38}$

Consumption of each country's own-good $\left(C_{H}, C_{F}^{*}\right)$ is in turn defined as a CES consumption index of its nontraded $\left(C_{H N}, C_{F N}^{*}\right)$ and traded own goods $\left(C_{H T}, C_{F T}^{*}\right)$ :

$$
\left(C_{H}\right)^{\frac{\phi-1}{\phi}}=\int_{0}^{n}\left(c_{H i}\right)^{\frac{\phi-1}{\phi}}+\int_{n}^{1}\left(c_{H i}\right)^{\frac{\phi-1}{\phi}} d i=\left(\frac{C_{H N}}{n}\right)^{\frac{\phi-1}{\phi}}+(1-n)\left(\frac{C_{H T}}{1-n}\right)^{\frac{\phi-1}{\phi}}
$$

where $C_{H N} \equiv\left[\left(\frac{1}{n}\right)^{\frac{1}{\phi}} \int_{0}^{n}\left(c_{H i}\right)^{\frac{\phi-1}{\phi}} d i\right]^{\frac{\phi}{\phi-1}}, \quad C_{H T} \equiv\left[\left(\frac{1}{1-n}\right)^{\frac{1}{\phi}} \int_{n}^{1}\left(c_{H i}\right)^{\frac{\phi-1}{\phi}} d i\right]^{\frac{\phi}{\phi-1}}$

and $\quad\left(C_{F}^{*}\right)^{\frac{\phi-1}{\phi}}=\int_{0}^{n^{*}}\left(c_{F i}^{*}\right)^{\frac{\phi-1}{\phi}}+\int_{n^{*}}^{1}\left(c_{F i}^{*}\right)^{\frac{\phi-1}{\phi}} d i=\left(n^{*}\right)\left(\frac{C_{F N}^{*}}{n^{*}}\right)^{\frac{\phi-1}{\phi}}+\left(1-n^{*}\right)\left(\frac{C_{F T}^{*}}{1-n^{*}}\right)^{\frac{\phi-1}{\phi}}$

where $C_{F N}^{*} \equiv\left[\left(\frac{1}{n^{*}}\right)^{\frac{1}{\phi}} \int_{0}^{n^{*}}\left(c_{F i}^{*}\right)^{\frac{\phi-1}{\phi}} d i\right]^{\frac{\phi}{\phi-1}}, \quad C_{F T}^{*} \equiv\left[\left(\frac{1}{1-n^{*}}\right)^{\frac{1}{\phi}} \int_{n^{*}}^{1}\left(c_{F i}^{*}\right)^{\frac{\phi-1}{\phi}} d i\right]^{\frac{\phi}{\phi-1}}$

and lower cases are used to denote consumption of individual varieties $i$ of each differentiated good. Again note that the elasticity of substitution $\phi$ is assumed constant within and across countries. ${ }^{39}$

${ }^{37}$ To derive (A1), define consumption by domestic resident of the home good and foreign traded good as $c_{H i}, i \in[0,1]$, and $c_{F T i}, i \in\left[0,1-n^{*}\right]$, respectively. We index all goods available for consumption in the domestic country by $j$ on the interval $\left[0,2-n^{*}\right]$, and order consumption as $c_{j}=c_{H i}$ for $j=i \in[0,1]$, and $c_{j}=c_{F i}$ for $j=i+1, j \in\left[1,2-n^{*}\right], i \in\left[0,1-n^{*}\right]$. Accordingly, we define aggregate consumption as

$$
\begin{aligned}
C^{\frac{\phi-1}{\phi}} & =\left(\frac{1}{2-n^{*}}\right)^{\frac{1}{\phi}}\left[\int_{0}^{1}\left(c_{j}\right)^{\frac{\phi-1}{\phi}} d j+\int_{1}^{2-n^{*}}\left(c_{j}\right)^{\frac{\phi-1}{\phi}} d j\right]=\left(\frac{1}{2-n^{*}}\right)^{\frac{1}{\phi}}\left(\frac{1}{1}\right)^{\frac{1}{\phi}} \int_{0}^{1}\left(c_{j}\right)^{\frac{\phi-1}{\phi}} d j+\left(\frac{1-n^{*}}{2-n^{*}}\right)^{\frac{1}{\phi}}\left(\frac{1}{1-n^{*}}\right)^{\frac{1}{\phi}} \int_{1}^{2-n^{*}}\left(c_{j}\right)^{\frac{\phi-1}{\phi}} d j \\
& =\left(\frac{1}{2-n^{*}}\right)^{\frac{1}{\phi}}\left(C_{H}\right)^{\frac{\phi-1}{\phi}}+\left(\frac{1-n^{*}}{2-n^{*}}\right)^{\frac{1}{\phi}}\left(C_{F T}\right)^{\frac{\phi-1}{\phi}}=\left(\theta\left[n^{*}\right]\right)^{\frac{1}{\phi}}\left(C_{H}\right)^{\frac{\phi-1}{\phi}}+\left(1-\theta\left[n^{*}\right]\right)^{\frac{1}{\phi}}\left(C_{F T}\right)^{\frac{\phi-1}{\phi}}
\end{aligned}
$$

The derivation of (A2) is analogous.

${ }^{38}$ Since the mass of home (foreign) goods is normalized to 1 , the bias coefficient of domestic (foreign) residents depends on $n^{*}(n)$ the number of varieties of the foreign (foreign) good that are imported.

${ }^{39}$ That is, $c_{H i} / c_{H j}=\left(p_{H i} / p_{H j}\right)^{-\phi}, c_{F i}^{*} / c_{F j}^{*}=\left(p_{F i}^{*} / p_{F j}^{*}\right)^{-\phi}$ for any two goods $i$ and $j$. 
Analogously, the consumption indices of the foreign good imported by domestic agents $C_{F T}$ and the home good imported by foreign agents $C_{H T}^{*}$ are defined as

$$
C_{F T} \equiv\left[\left(\frac{1}{1-n^{*}}\right)^{\frac{1}{\phi}} \int_{n^{*}}^{1}\left(c_{F i}\right)^{\frac{\phi-1}{\phi}} d i\right]^{\frac{\phi}{\phi-1}}, C_{H T}^{*} \equiv\left[\left(\frac{1}{1-n}\right)^{\frac{1}{\phi}} \int_{n}^{1}\left(c_{H i}^{*}\right)^{\frac{\phi-1}{\phi}} d i\right]^{\frac{\phi}{\phi-1}}
$$

Prices and Relative Demands

Price indexes are defined as usual for each category of goods, in correspondence to the consumption indexes above:

$$
P=\left(\theta\left[n^{*}\right]\left(P_{H}\right)^{1-\phi}+\left(1-\theta\left[n^{*}\right]\right)\left(P_{F T}\right)^{1-\phi}\right)^{\frac{1}{1-\phi}}
$$

where $P_{H}^{1-\phi}=\int_{0}^{n}\left(p_{H i}\right)^{1-\phi} d i+\int_{n}^{1}\left(p_{H i}\right)^{1-\phi} d i=n\left(P_{H N}\right)^{1-\phi}+(1-n)\left(P_{H T}\right)^{1-\phi}$

$$
\begin{aligned}
& P_{H N} \equiv\left(\left(\frac{1}{n}\right) \int_{0}^{n} p_{H i}^{1-\phi} d i\right)^{\frac{1}{1-\phi}}, \quad P_{H T} \equiv\left(\left(\frac{1}{1-n}\right) \int_{n}^{1} p_{H i}^{1-\phi} d i\right)^{\frac{1}{1-\phi}} \\
& P_{F T} \equiv\left(\left(\frac{1}{1-n^{*}}\right) \int_{n^{*}}^{1} p_{F i}^{1-\phi} d i\right)^{\frac{1}{1-\phi}}
\end{aligned}
$$

where $P$ is the aggregate price level, $P_{H}$ is the price index of all home goods, $P_{H N}$ is the price index of nontraded home goods, $P_{H T}$ is the price index of traded home goods, and $P_{F T}$ is the price (to domestic residents) of imported foreign goods.

Correspondingly,

$$
P^{*}=\left((\theta[n])\left(P_{F}^{*}\right)^{1-\phi}+(1-\theta[n])\left(P_{H T}^{*}\right)^{1-\phi}\right)^{\frac{1}{1-\phi}}
$$

where $\left(P_{F}^{*}\right)^{1-\phi}=\int_{0}^{n^{*}}\left(p_{F i}^{*}\right)^{1-\phi} d j+\int_{n^{*}}^{1}\left(p_{F i}^{*}\right)^{1-\phi} d i=\left(n^{*}\right)\left(P_{F N}^{*}\right)^{1-\phi}+\left(1-n^{*}\right)\left(P_{F T}^{*}\right)^{1-\phi}$

$$
\begin{aligned}
& P_{F N}^{*} \equiv\left[\left(\frac{1}{n^{*}}\right)^{n^{*}} \int_{0}^{*}\left(p_{F i}^{*}\right)^{1-\phi} d i\right]^{\frac{1}{1-\phi}}, \quad P_{F T}^{*} \equiv\left[\left(\frac{1}{1-n^{*}}\right)_{n^{*}}^{1} \int\left(p_{F i}^{*}\right)^{1-\phi} d i\right]^{\frac{1}{1-\phi}} \\
& P_{H T}^{*} \equiv\left[\left(\frac{1}{1-n}\right)^{1} \int_{n}\left(p_{H i}^{*}\right)^{1-\phi} d i\right]^{\frac{1}{1-\phi}}
\end{aligned}
$$

Note that the consumption and price indices imply the following relative demand functions for domestic residents: ${ }^{40}$

$$
\begin{array}{ll}
C_{H} / C=\left(\theta\left[n^{*}\right]\right)\left(P_{H} / P\right)^{-\phi}, & C_{F T} / C=\left(1-\theta\left[n^{*}\right]\right)\left(P_{F T} / P\right)^{-\phi} \\
C_{H N} / C_{H}=n\left(P_{H N} / P_{H}\right)^{-\phi}, & C_{H T} / C_{H}=(1-n)\left(P_{H T} / P_{H}\right)^{-\phi}
\end{array}
$$

and for foreign residents:

\footnotetext{
${ }^{40}$ Also note that the CES specification implies for individual goods variety $i$ $c_{H i} / C_{H}=\left(p_{H i} / P_{H}\right)^{-\phi}, c_{H i} / C_{H T}=(1-n)^{-1}\left(p_{H i} / P_{H T}\right)^{-\phi}, c_{H i}^{*} / C_{H T}^{*}=(1-n)^{-1}\left(p_{H i}^{*} / P_{H T}^{*}\right)^{-\phi}$ and $c_{F i}^{*} / C_{F}^{*}=\left(p_{F i}^{*} / P_{F}^{*}\right)^{-\phi}, c_{F i}^{*} / C_{F T}^{*}=\left(1-n^{*}\right)^{-1}\left(p_{F i}^{*} / P_{F T}^{*}\right)^{-\phi}, c_{F i} / C_{F T}=\left(1-n^{*}\right)^{-1}\left(p_{F i} / P_{F T}\right)^{-\phi}$.
} 


$$
\begin{array}{ll}
C_{F}^{*} / C^{*}=(\theta[n])\left(P_{F}^{*} / P^{*}\right)^{-\phi}, \quad & C_{H T}^{*} / C^{*}=(1-\theta[n])\left(P_{H T}^{*} / P^{*}\right)^{-\phi} \\
C_{F N}^{*} / C_{F}^{*}=\left(n^{*}\right)\left(P_{F N}^{*} / P_{F}^{*}\right)^{-\phi}, & C_{F T}^{*} / C_{F}^{*}=\left(1-n^{*}\right)\left(P_{F T}^{*} / P_{F}^{*}\right)^{-\phi}
\end{array}
$$

Production and Productivity

The production sector in each country consists of constant-returns-to-scale technologies for the output of each differentiated good:

$$
y_{H i}=A_{i} l_{H i}, \quad y_{F i}=A_{i}^{*} l_{F i}
$$

where $y_{H i}, y_{F i}$ represent the level of output, $l_{H i}, l_{F i}$ denote workers employed in production, and $A_{i}, A_{i}^{*}$ are productivity coefficients for each individual good $i$. We employ the usual assumption that labor is mobile across sectors within each economy, but immobile across countries.

Profit maximization under monopolistic competition implies pricing is determined by the standard cost markup rule:

$$
p_{H i}=p_{H i}^{*}=\frac{\varphi}{\varphi-1} \frac{W}{A_{i}}, \quad p_{F i}=p_{F i}^{*}=\frac{\varphi}{\varphi-1} \frac{W^{*}}{A_{i}^{*}}
$$

where $W, W^{*}$ denote the home and foreign wage rates, respectively, and $\varphi /(1-\varphi)$ is the markup factor. Note that the markup is assumed to depend on an elasticity of substitution parameter $\varphi$ that differs from that across varieties of goods $\phi .{ }^{41}$ Note also that, in the absence of transport costs, sales prices are equalized across markets for each good $i .^{42}{ }^{43}$

Firms in the domestic (foreign) country have a distribution of productivity levels over $\left[A_{\min }, A_{\max }\right]\left(\left[A_{\min }^{*}, A_{\max }^{*}\right]\right.$ given by $F\left[A_{i}\right]\left(F\left[A_{i}^{*}\right]\right)$. Among these firms, $1-n=F\left[A_{n}\right]$ $\left(1-n^{*}=F\left[A_{n}^{*}\right]\right)$ are exporters. These exporters have a distribution of productivity levels $\left[A_{n}, A_{\max }\right]\left(\left[A_{n}^{*}, A_{\max }^{*}\right]\right)$ given by the conditional distribution $F\left[A_{i}\right]\left(F\left[A_{i}^{*}\right]\right)$ on these intervals. We define special (weighted) productivity averages for home goods $\tilde{A}$, nontraded home goods $\tilde{A}_{N}$, and traded home goods $\tilde{A}_{T}$ and their foreign analogues ${ }^{44}$

$$
\begin{array}{ll}
(\tilde{A})^{\phi-1} \equiv \int_{0}^{1} A_{i}^{\phi-1} d i, & \left(\tilde{A}^{*}\right)^{\phi-1} \equiv \int_{0}^{1}\left(A_{i}^{*}\right)^{\phi-1} d i \\
\left(\tilde{A}_{N}[n]\right)^{\phi-1} \equiv \frac{1}{n} \int_{0}^{n}\left(A_{i}\right)^{\phi-1} d i, & \left(\tilde{A}_{N}^{*}\left[n^{*}\right]\right)^{\phi-1} \equiv\left(\frac{1}{n^{*}}\right)_{0}^{n^{*}} \int_{0}\left(A_{i}^{*}\right)^{\phi-1} d i \\
\left(\tilde{A}_{T}[n]\right)^{\phi-1} \equiv\left(\frac{1}{1-n}\right) \int_{n}^{1} A_{i}^{\phi-1} d i, & \left(\tilde{A}_{T}^{*}\left[n^{*}\right]\right)^{\phi-1} \equiv\left(\frac{1}{1-n^{*}}\right) \int_{n^{*}}^{1}\left(A_{i}^{*}\right)^{\phi-1} d i
\end{array}
$$

\footnotetext{
${ }^{41}$ In our simulations we assume that $\phi<\varphi$ on the presumption that the elasticity of substitution among firms in a given sector (e.g. between Honda and Toyota) is greater than that across sectors (e.g. between autos and food).

${ }^{42}$ The introduction of good-specific iceberg costs trade costs creates a gap between the domestic and foreign sales price: $p_{H i}^{*}=p_{H i} /\left(1-\tau_{i}\right)$, where $\tau_{i}$ denotes the fraction of good $i$ that disappears in transport.

${ }^{43}$ Bergin and Glick (2004) show that the extension to good-specific iceberg shipping costs introduces similar terms to these in the markup calculation, but that the derivation of equilibrium is analogous once export goods' productivities are adjusted for the iceberg loss.

${ }^{44}$ As pointed out by Melitz (2003), weighting by the elasticity parameter $\phi$, makes the weights proportional to the relative output shares of firms.
} 
Note that $\tilde{A}$ is independent of $n$, while $\tilde{A}_{N}$, and $\tilde{A}_{T}$ are not. If goods are ordered with increasing productivity, then $\partial \tilde{A}_{T} / \partial n>0, \partial \tilde{A}_{N} / \partial n<0$, i.e. average productivity rises (falls) in the traded sector (nontraded) sector with increasing $n$. Intuitively, as the share of nontraded goods in the economy rises, goods at the low productivity end of the traded goods sector become nontraded, and the average level of productivity of all remaining traded goods rises. ${ }^{45}$

In simulations, we assume the firm-specific component of productivity follows a Fréchet distribution in logs, and also assume a productivity component $\alpha$ which is common to all firms, so that total productivity is

$$
A_{i}=a_{i} \alpha, \quad A_{i}^{*}=a_{i}^{*} \alpha^{*} .
$$

It is straightforward to express the price index for nontraded and traded home goods in terms of these productivity averages by using (A14) to substitute for $p_{H i}$ in (A8):

$$
\begin{aligned}
& P_{H N}=\left(\left(\frac{1}{n}\right)\left[\int_{0}^{n}\left(\frac{\varphi}{\varphi-1} \frac{W}{A_{i}}\right)^{1-\phi} d i\right]\right)^{\frac{1}{1-\phi}}=\frac{\varphi}{\varphi-1}\left(\frac{W}{\tilde{A}_{N}[n]}\right) \\
& P_{H T}=P_{H T}^{*}=\left(\left(\frac{1}{1-n}\right)\left[\int_{n}^{1}\left(\frac{\varphi}{\varphi-1} \frac{W}{A_{i}}\right)^{1-\phi} d i\right]\right)^{\frac{1}{1-\phi}}=\left(\frac{\varphi}{\varphi-1}\right) \frac{W}{\tilde{A}_{T}[n]}
\end{aligned}
$$

with (A7) implying

$$
P_{H}=\frac{\varphi}{\varphi-1} \frac{W}{\tilde{A}}
$$

Equations (A19) and (A20) express the prices of nontraded and traded goods as functions of the share of nontraded goods $n$, the elasticity of substitution across domestic goods $\phi$, the wage rate $W$, and the productivity averages. Observe that these prices are increasing in the wage rate and decreasing in the average productivity. Keep in mind that $n$ is itself an endogenous variable that will be solved as part of the general equilibrium system. Since $\tilde{A}$ is independent of $n$, the nontraded vs. traded goods composition of the economy affects $P_{H}$ only through its effect on the average wage level in the economy. ${ }^{46}$ The foreign counterparts are

$$
\begin{aligned}
& P_{F N}^{*}=\frac{\varphi}{\varphi-1}\left(\frac{W^{*}}{\tilde{A}_{N}^{*}\left[n^{*}\right]}\right) \\
& P_{F T}^{*}=P_{F T}=\frac{\varphi}{\varphi-1}\left(\frac{W^{*}}{\tilde{A}_{T}^{*}\left[n^{*}\right]}\right) \\
& P_{F}^{*}=\frac{\varphi}{\varphi-1}\left(\frac{W^{*}}{\tilde{A}^{*}}\right)
\end{aligned}
$$

${ }^{45}$ Note $(\tilde{A})^{\phi-1}=n\left(\tilde{A}_{N}[n]\right)^{\phi-1}+(1-n)\left(\tilde{A}_{T}[n]\right)^{\phi-1}$. It is straightforward to demonstrate $\partial\left((1-n)\left(\tilde{A}_{T}[n]\right)^{\phi-1}\right) / \partial n<0$.

${ }^{46}$ In the absence of any transport costs at all, all goods are traded ( $\left.n=0\right)$, implying $\tilde{A}=\tilde{A}_{T}$, and $P_{H}=P_{H T}=P_{H T}^{*}$. 


\section{Marginal Trading Condition}

To pin down the equilibrium share of nontraded goods. note that at the margin the producers of the borderline nontraded--nontraded good must be indifferent between home and foreign sales. That is, the (real) operating profits from exporting the $n$th home good must equal the (real) fixed cost of exporting $f_{X}$ :

$$
\left(p_{H n}^{*}-\frac{W}{A_{n}}\right)\left(\frac{1}{P}\right) c_{H n}^{*}=\left(\frac{W}{P}\right) f_{X}
$$

where the operating profits are defined as the export price minus marginal cost, times the volume of sales to foreign residents. Note that real operating profits are expressed in terms of the price of the domestic consumption basket $P$. We follow Ghironi and Melitz (2003) in assuming that firms employ domestic workers to cover the fixed costs. With $f_{X}$ measured in units of effective domestic labor, we define $W / P$ as the effective real wage rate of this labor and express these labor costs as $(W / P) f_{X}{ }^{47}$

$$
\text { Since the condition } c_{H i}^{*} / C_{H T}^{*}=(1-n)^{-1}\left(p_{H i}^{*} / P_{H T}^{*}\right)^{-\phi} \text { holds for all goods } i \text { in the }
$$

range $[n, 1]$, it can be used to substitute for $c_{H n}^{*}$ in (A22). Canceling the variable $P$ from both sides, substituting for $p_{H n}^{*}$ with (A14), multiplying and dividing by $P_{H T}^{*}$, and lastly substituting with (20) for $P_{H T}^{*}$ in the denominator on the lefthand side gives

$$
\left[\left(\frac{1}{\varphi}\right)\left(\frac{A_{n}}{\tilde{A}_{T}[n]}\right)^{\phi-1}\left(\frac{1}{1-n}\right)\right] P_{H T}^{*} C_{H T}^{*}=W f_{X}
$$

Observe that export profits depend on the productivity of the marginally traded $n$th good $A_{n}$, relative to the average of all exported goods, $\tilde{A}_{T}[n]$. For given aggregate export sales $P_{H T}^{*} C_{H T}^{*}$, when no goods are traded ( $n=1)$, the marginal profitability of exporting is very high. As long as profits exceed the fixed costs of exporting, more goods will become traded and $n$ declines. As $n$ falls, the relative productivity and profitability of the marginal exported good declines; in equilibrium profits are reduced to just covering the fixed costs of the $n$th good entering into the foreign export market. Note that a balanced change in productivity for all home goods, leaving $A_{n} / \tilde{A}_{T}$ unchanged, does not effect the marginal profitability of exports.

The marginal trading condition for the foreign good is

$$
\left[\left(\frac{1}{\varphi}\right)\left(\frac{A_{n}^{*}}{\tilde{A}_{T}^{*}\left[n^{*}\right]}\right)^{\phi-1}\left(\frac{1}{1-n^{*}}\right)\right] P_{F T} C_{F T}=W^{*} f_{X}^{*}
$$

\footnotetext{
${ }^{47}$ In general, the effective labor employed to cover the fixed costs should depend on the productivity of the labor employed and the real wage rate should be scaled by this level of productivity, which we can denote $A_{f X}$. $A_{f X}$ may be assumed exogenously given or related to productivity elsewhere in the economy, e.g. $\tilde{A}$, the average aggregate productivity level. We abstract from this issue by normalizing $A_{f X}$ to 1 .
} 
Labor market equilibrium

Labor market equilibrium in the domestic country requires that labor employed in production of nontraded and traded home goods plus labor employed to cover the fixed costs of exporting equal the (exogenous) domestic labor supply $L_{H}{ }^{48}$ :

$$
\int_{0}^{n} l_{H i} d i+\int_{n}^{1} l_{H i} d i+(1-n) f_{X}=L_{H}
$$

Substituting for $l_{H i}$ with the production function (A13):

$$
\begin{aligned}
& \int_{0}^{n} \frac{y_{H i}}{A_{i}} d i+\int_{n}^{1} \frac{y_{H i}}{A_{i}} d i+(1-n) f_{X}=L_{H} \text { or } \\
& \int_{0}^{n} \frac{c_{H i}}{A_{i}} d i+\int_{n}^{1} \frac{c_{H i}+c_{H i}^{*}}{A_{i}} d i+(1-n) f_{X}=L_{H}
\end{aligned}
$$

since $y_{H i}=c_{H i}$ for $i \in[0, n], \quad y_{H i}=c_{H i}+c_{H i}^{*}$ for $i \in[n, 1]$ Substituting with

$$
c_{H i} / C_{H}=\left(p_{H i} / P_{H}\right)^{-\phi} \text { and } c_{H i}^{*} / C_{H T}^{*}=(1-n)^{-1}\left(p_{H i}^{*} / P_{H T}^{*}\right)^{-\phi}
$$

gives

$$
\int_{0}^{n} \frac{C_{H}}{A_{i}}\left(\frac{p_{H i}}{P_{H}}\right)^{-\phi} d i+\int_{n}^{1}\left(\frac{1}{A_{i}}\right)\left[C_{H}\left(\frac{p_{H i}}{P_{H}}\right)^{-\phi}+\left(\frac{1}{1-n}\right) C_{H T}^{*}\left(\frac{p_{H i}^{*}}{P_{H T}^{*}}\right)^{-\phi}\right] d i+(1-n) f_{X}=L_{H}
$$

Using (A14) and (A15) in turn to substitute for $p_{H i}, p_{H i}^{*}$ and (A16) and (A25) to substitute for the definitions of $\tilde{A}, \tilde{A}_{T}[n]$ gives

$$
W=\left(L_{H}-(1-n) f_{X}\right)^{-1 / \phi}\left(\frac{\varphi-1}{\varphi}\right)\left[\left(\frac{P_{H} C_{H}}{\left(P_{H}\right)^{1-\phi}}\right)(\tilde{A})^{\phi-1}+\left(\frac{P_{H T}^{*} C_{H T}^{*}}{\left(P_{H T}^{*}\right)^{1-\phi}}\right)\left(\tilde{A}_{T}[n]\right)^{\phi-1}\right]^{\frac{1}{\phi}}
$$

Substituting for $P_{H}, P_{H T}^{*}$ with (A21), (A20) and canceling terms gives

$$
W=\left(L_{H}-(1-n) f_{X}\right)^{-1 / \phi}\left(\frac{\varphi-1}{\varphi}\right)\left[\left(\frac{P_{H} C_{H}}{\left(\frac{\varphi}{\varphi-1} \frac{W}{\tilde{A}}\right)^{1-\phi}}\right)(\tilde{A})^{\phi-1}+\left(\frac{P_{H T}^{*} C_{H T}^{*}}{\left(\frac{\varphi}{\varphi-1} \frac{W}{\tilde{A}_{T}[n]}\right)^{1-\phi}}\right)\left(\tilde{A}_{T}[n]\right)^{\phi-1}\right]^{\frac{1}{\phi}}
$$

implying

$$
W L_{H}-(1-n) f_{X} W=\left(\frac{\varphi-1}{\varphi}\right)\left[P_{H} C_{H}+P_{H T}^{*} C_{H T}^{*}\right]
$$

i.e. the domestic wage bill -- net of wages paid for workers employed in covering fixed costs, $W(1-n) f_{X}$-- is proportional to the value of home goods consumed domestically or exported, with the proportionality constant equal to 1 minus the profit rate $1 / \varphi$.

Correspondingly, for the foreign country

$$
W^{*}=\left(L_{F}-\left(1-n^{*}\right) f_{X}^{*}\right)^{-1 / \phi}\left(\frac{\varphi-1}{\varphi}\right)\left[\left(\frac{P_{F}^{*} C_{F}^{*}}{\left(P_{F}^{*}\right)^{1-\phi}}\right)\left(\tilde{A}^{*}\right)^{\phi-1}+\left(\frac{P_{F T} C_{F T}}{\left(P_{F T}\right)^{1-\phi}}\right)\left(\tilde{A}_{F}^{*}\left[n^{*}\right]\right)^{\phi-1}\right]^{\frac{1}{\phi}}
$$

\footnotetext{
${ }^{48}$ When all home goods are nontraded, i.e. $n=1$, then no labor is employed to cover fixed costs of exporting.
} 


$$
W^{*} L_{F}-\left(1-n^{*}\right) f_{X}^{*} W^{*}=\left(\frac{\varphi-1}{\varphi}\right)\left[P_{F}^{*} C_{F}^{*}+P_{F T} C_{F T}\right]
$$

Closing the Model

We close the model with the balanced trade condition that the value of exports equals the value of imports

$$
P_{H T}^{*} C_{H T}^{*}=P_{F T} C_{F T}
$$

and the normalization condition ${ }^{49}$

$$
P^{*}=1
$$

Equilibrium determines the 24 variables $C, C_{H}, C_{H N}, C_{H T}, C_{F T} P, P_{H}, P_{H N}, P_{H T}, P_{F T}, W$, and $n$ and their foreign counterparts (denoted by $*$ ) by solving the system of 24 equations (A1)(A7), (A19)-(A20), (A23), and (A26) plus their foreign counterparts, together with (A27) and (A28).

\section{$\underline{\text { Relative Prices }}$}

Further insights may be obtained by developing relative price expressions in terms of productivity averages. The terms of trade between home and foreign export goods -- the price of home country exports relative to its imports - is obtained from (A20) and (A20*):

$$
\left(\frac{P_{H T}^{*}}{P_{F T}}\right)=\frac{W / \tilde{A}_{T}[n]}{W^{*} / \tilde{A}_{T}^{*}\left[n^{*}\right]},
$$

and is equal to the ratio of marginal costs of exporting in each country, which in turn depend on relative wages and (inversely) on the average effective productivity of traded goods in each country. It can be seen readily that the terms of trade depends on $n$ through its effect on tradables productivity: if a ceteris paribus increase in $n$ raises the productivity of home traded goods $\left(\partial \tilde{A}_{T} / \partial n>0\right)$, the home country's terms of trade declines.

To derive an expression for the real exchange rate in the model, note that relative demand conditions (A11) and (A11*) imply

$$
P_{F T} C_{F T}=(1-\theta[n])\left(P_{F T}\right)^{1-\phi} P^{\phi} C, \quad P_{H T}^{*} C_{H T}^{*}=(1-\theta[n])\left(P_{H T}^{*}\right)^{1-\phi}\left(P^{*}\right)^{\phi} C^{*}
$$

Combining with the balanced trade condition (A29) and defining the real exchange rate as $P / P^{*}$ (units of the domestic consumption basket per unit of foreign consumption) yields

$$
\frac{P}{P^{*}}=\left(\frac{P_{H T}^{*}}{P_{F T}}\right)^{\frac{1-\phi}{\phi}}\left(\frac{C}{C^{*}}\right)^{-1 / \phi}
$$

i.e. the real exchange rate depreciates (since $\phi>1$ ) in response to a rise in the terms of trade $P_{H T}^{*} / P_{F T}$ and/or rise in relative domestic consumption $C / C^{*}$ in order to maintain trade balance.

An alternative expression for the real exchange rate is obtained by using (A21), (A20), $\left(\mathrm{A} 21^{*}\right),\left(\mathrm{A} 20^{*}\right)$ to substitute for $P_{H}, P_{H T}^{*}, P_{F}^{*}, P_{F T}$, respectively in the definitions of $P, P^{*}$ given by $(\mathrm{A} 6),\left(\mathrm{A} 6^{*}\right)$

$$
\left(\frac{P}{P^{*}}\right)^{\phi-1}=\left(\frac{\theta[n]\left(\frac{W / \tilde{A}}{W^{*} / \tilde{A}^{*}}\right)^{\phi-1}+(1-\theta[n])\left(\frac{\tilde{A}_{T}[n]}{\tilde{A}}\right)^{\phi-1}}{\theta\left[n^{*}\right]+\left(1-\theta\left[n^{*}\right]\right)\left(\frac{\tilde{A}_{T}^{*}\left[n^{*}\right]}{\tilde{A}^{*}} \cdot \frac{W / \tilde{A}}{W^{*} / \tilde{A}^{*}}\right)^{\phi-1}}\right)
$$

This expression is analyzed and interpreted in the main text.

\footnotetext{
${ }^{49}$ An alternative normalization is $W^{*}=1$.
} 


\section{References}

Asea, Patrick K., and W. Max Corden. 1994. The Balassa-Samuelson Model: An Overview. Review of International Economics 2 (October): 191-200.

Balassa, Bela. 1964. The Purchasing-Power Parity Doctrine: A Reappraisal. Journal of Political Economy 72 (December): 584-96.

Bergin, Paul R., and Reuven Glick. 2003. Endogenous Nontradability and Macroeconomic Implications. Working Paper Series no. 9739, National Bureau of Economic Research (June).

Bergin, Paul R., and Reuven Glick. 2004. Tradability, Productivity, and Understanding International Integration. University of California at Davis mimeo.

Bernard, Andrew B., and J. Bradford Jensen. 1999. Exporting and Productivity. Working Paper Series no. 7135, National Bureau of Economic Research (May).

Bhagwati, Jagdish N. 1984. Why are Services Cheaper in the Poor Countries? Economic Journal 94 (June): 279-86.

Broadberry, Stephen, and Bishnupriya Gupta. 2003. The Early Modern Great Divergence: Wages, Prices and Economic Development in Europe and Asia, 1500-1800. Department of Economics, University of Warwick. Photocopy (August).

Burstein, Ariel, João Neves, and Sergio Rebelo. 2002. Distribution Costs and Real Exchange Rate Dynamics. Journal of Monetary Economics.

Chinn, Menzie D. 2000. The Usual Suspects? Productivity and Demand Shocks and Asia-Pacific Real Exchange Rates. Review of International Economics 8: 20-43.

Chinn, Menzie D., and Louis Johnston. 1996. Real Exchange Rate Levels, Productivity and Demand Shocks. Working Paper Series no. 5709, National Bureau of Economic Research (August).

Clague, Christopher, and Vito Tanzi. 1972. Human Capital, Natural Resources and the Purchasing-Power Parity Doctrine: Some Empirical Results. Economia Internazionale 25 (February): 3-18.

Clark, Gregory. 2002. The Great Escape: The Industrial Revolution in Theory and History. UC Davis (October). Photocopy.

Clark, Gregory. 2003. The Industrial Revolution in England. UC Davis (August). Photocopy. Chapter 8 in [book manuscript].

Clements, Kenneth W., and M. Semudram. 1983. An International Comparison of the Price of Nontraded Goods. Weltwirtschaftliches Archiv 117: 356-63.

Crafts, Nicholas F. R. 1985. British Economic Growth during the Industrial Revolution. Oxford: Clarendon Press.

De Gregorio, Jose, Alberto Giovannini, and Holger C. Wolf. 1994. International Evidence on Tradable and Nontradables Inflation. European Economic Review 38: 1225-44.

De Gregorio, Jose, and Holger C. Wolf. 1994. Terms of Trade, Productivity, and the Real Exchange Rate. Working Paper Series no. 4807, National Bureau of Economic Research (July).

De Long, J. Bradford. 1988. Productivity Growth, Convergence, and Welfare: Comment. American Economic Review 78 (December): 1138-54. 
Dornbusch, Rudiger, Stanley Fischer, and Paul A. Samuelson. 1977. Comparative Advantage, Trade, and Payments in a Ricardian Model with a Continuum of Goods. American Economic Review 67 (December): 823-39.

Eaton, Jonathan, and Samuel Kortum. 2002. Technology, Geography, and Trade. Econometrica 70 (September): 1741-79.

Estevadeordal, Antoni, Brian Frantz, and Alan M. Taylor. 2003. The Rise and Fall of World Trade, 1870-1939. Quarterly Journal of Economics 118 (May): 359-407.

Feenstra, Robert C. 1998. Integration of Trade and Disintegration of Production in the Global Economy. Journal of Economic Perspectives 12 (Fall): 31-50.

Findlay, Ronald, and Kevin H. O'Rourke. 2003. Commodity Market Integration, 1500-2000. In Globalization in Historical Perspective, edited by Michael D. Bordo, Alan M. Taylor and Jeffrey G. Williamson. Chicago: University of Chicago Press.

Fitzgerald, Doireann. 2003. Terms-of-Trade Effects, Interdependence and Cross-Country Differences in Price Levels. Photocopy. Harvard University (January).

Froot, Kenneth A., and Kenneth Rogoff. 1995. Perspectives on PPP and Long-Run Real Exchange Rates. In Handbook of International Economics, vol. 3, edited by Gene Grossman and Kenneth Rogoff. Amsterdam: North Holland.

Galor, Oded, and Andrew Mountford. 2003. Why are a Third of People Indian and Chinese? Trade, Industrialization and Demographic Transition. Brown University Working Paper No. 38-01 (January).

Galor, Oded, and David N. Weil. 2000. Population, Technology, and Growth: From Malthusian Stagnation to the Demographic Transition and Beyond. American Economic Review 90 (September): 806-28.

Ghironi, Fabio, and Marc J. Melitz, 2003. International Trade and Macroeconomic Dynamics with Heterogeneous Firms, Boston College mimeo.

Hall, Robert E., and Charles I. Jones. 1999. Why Do Some Countries Produce So Much More Output per Worker than Others? Quarterly Journal of Economics 114 (February): 83116.

Hansen, Gary D. and Prescott, Edward C. 2002. Malthus to Solow. American Economic Review 92 (September): 1205-17.

Harley, C. Knick. 1982. British Industrialization Before 1841: Evidence of Slower Growth During the Industrial Revolution. Journal of Economic History 42 (June): 267-89.

Harley, C. Knick. 1993. Reassessing the Industrial Revolution: A Macro View. In The British Industrial Revolution: An Economic Perspective, edited by Joel Mokyr. Boulder, Colo.: Westview Press.

Harley, C. Knick, and Nicholas F. R. Crafts. 2000. Simulating the Two Views of the British Industrial Revolution. Journal of Economic History 60 (September): 819-41.

Hau, Harald. 2002. Real Exchange Rate Volatility and Economic Openness: Theory and Evidence. Journal of Money, Credit and Banking 34 (August): 611-30.

Helpman, Elhanan, Marc J. Melitz, and Stephen R. Yeaple. 2002. Export versus FDI. Photocopy. Harvard University (November).

Hsieh, David. 1982. The Determination of the Real Exchange Rate: The Productivity Approach. Journal of International Economics 12 (May): 355-62. 
Irwin, Douglas A. 1988. Welfare Effects of British Free Trade: Debate and Evidence from the 1840s. Journal of Political Economy 96: 1142-65.

Irwin, Douglas A. 1996. The United States in a New Global Economy? A Century's Perspective. American Economic Review 82 (May): 41-46.

Ito, Takatoshi, Peter Isard, and Steven Symansky. 1999. Economic Growth and Real Exchange Rate: An Overview of the Balassa-Samuelson Hypothesis in Asia. In Changes in Exchange Rates in Rapidly Developing Countries: Theory, Practice, and Policy Issues edited by Takatoshi Ito and Anne O. Krueger. Chicago: University of Chicago Press.

Jones, Charles I. 1999. Was the Industrial Revolution Inevitable? Economic Growth Over the Very Long Run. Working Paper Series no. 7375, National Bureau of Economic Research (October).

Jorgenson, Dale W., and Kevin J. Stiroh. 2000. U.S. Economic Growth at the Industry Level. American Economic Review 90 (May): 161-67.

Lewis, W. Arthur. 1978. The Evolution of the International Economic Order. Princeton, N.J.: Princeton University Press.

Lothian, James R., and Mark P. Taylor. 2003. Real Exchange Rates Over the Past Two Centuries: How Important is the Harrod-Balassa-Samuelson Effect? Warwick University. Photocopy.

Lucas, Robert E. 1988. On the Mechanics of Economic Development. Journal of Monetary Economics 22 (July): 3-42.

Lucas, Robert E. 2002. Lectures on Economic Growth. Cambridge: Harvard University Press. Maddison, Angus. 1995. Monitoring the World Economy. Paris: OECD.

Maddison, Angus. 2001. The World Economy: A Millennial Perspective. Development Centre Studies Paris: OECD.

Marston, Richard C. 1990. Systematic Movements in Real Exchange Rates in the G-5: Evidence on the Integration of Internal and External Markets. Journal of Banking and Finance 14 (November): 1023-44.

Matsuyama, Kiminori. 1992. Agricultural Productivity, Comparative Advantage, and Economic Growth. Journal of Economic Theory 58: 317-34.

McCloskey, Donald N. 1981. The Industrial Revolution 1780-1860: A Survey. In The Economic History of Britain Since 1700, vol. 1, edited by Roderick C. Floud and Donald N. McCloskey. Cambridge: Cambridge University Press.

Melitz, Marc. 2003. The Impact of Trade on Intra-Industry Reallocations and Aggregate Industry Productivity. Econometrica 71: 1695-1726.

Micossi, Stefano, and Gian Maria Milesi-Ferretti. 1994. Real Exchange Rates and the Prices of Nontradable Goods. Working Papers no. 94/19, International Monetary Fund.

Obstfeld, Maurice. 2001. International Macroeconomics: Beyond the Mundell-Fleming Model. IMF Staff Papers 47 (Special Issue).

O'Connell, Paul G. J. 1998. The Overvaluation of Purchasing Power Parity. Journal of International Economics 44 (February): 1-19.

Officer, Lawrence H. 1982. Purchasing Power Parity and Exchange Rates: Theory, Evidence and Relevance. Greenwich, Conn.: JAI Press. 
Prados de la Escosura, Leandro. 2000. International Comparisons of Real Product, 1820-1990: An Alternative Data Set. Explorations in Economic History 37 (April): 1-41.

Richardson, J. David, and Karin Rindal. 1996. Why exports matter: More! Washington, D.C.: Institute for International Economics.

Sachs, Jeffrey D. 1999. Helping the World's Poorest. The Economist (August 12).

Samuelson, Paul A. 1964. Theoretical Notes on Trade Problems. Review of Economics and Statistics 46 (May): 145-54.

Samuelson, Paul A. 1994. Facets of Balassa-Samuelson Thirty Years Later. Review of International Economics 2 (October): 201-26.

Sarno, Lucio, and Mark P. Taylor. 2002. The Economics of Exchange Rates. Cambridge: Cambridge University Press.

Temin, Peter. 1997. Two Views of the British Industrial Revolution. Journal of Economic History 57 (March): 63-82.

Temin, Peter. 2000. A Response to Harley and Crafts. Journal of Economic History 60 (September): 842-46.

Voth, Hans-Joachim. 2003. Living Standards During the Industrial Revolution: An Economist's Guide. American Economic Review 93 (May): 221-26.

Ward, Marianne, and John Devereux. 2003 New Evidence on Catch-Up and Convergence Since 1872. Working Paper. Loyola College, Maryland.

Williamson, Jeffrey G. 1987. Debating the British Industrial Revolution. Explorations in Economic History 24 (July): 269-92.

Williamson, Jeffrey G. 1990. The Impact of the Corn Laws Just Prior to Repeal. Explorations in Economic History 27 (April): 123-56.

Yi, Kei-Mu. 2003. Can Vertical Specialization Explain the Growth of World Trade? Journal of Political Economy 111 (February): 52-102. 
Table 1: The Balassa-Samuelson Effect in History

OLS regression of the log relative price level on log relative real income per capita

\begin{tabular}{|c|c|c|c|c|}
\hline Year(s) & Sources & $N$ & $\beta$ & s.e. \\
\hline \multicolumn{5}{|c|}{ (a) Postwar Sample 1950-2000 } \\
\hline 1950 & PWT & 53 & 0.08 & $(0.07)$ \\
\hline 1955 & PWT & 69 & 0.11 & $(0.07)$ \\
\hline 1960 & PWT & 108 & 0.19 & $(0.05) * * *$ \\
\hline 1965 & PWT & 109 & 0.20 & $(0.05)^{* * *}$ \\
\hline 1970 & PWT & 111 & 0.20 & $(0.05)^{* \star *}$ \\
\hline 1975 & PWT & 112 & 0.20 & $(0.05)^{* * *}$ \\
\hline 1980 & PWT & 118 & 0.20 & $(0.05)^{* * *}$ \\
\hline 1985 & PWT & 118 & 0.27 & $(0.04) * * *$ \\
\hline 1990 & PWT & 128 & 0.36 & $(0.04) * * *$ \\
\hline 1995 & PWT & 142 & 0.41 & $(0.04)^{* * *}$ \\
\hline \multicolumn{5}{|c|}{ (b) Historical Sample 1870-1990 } \\
\hline 1870 & Taylor/PWT/Maddison & 7 & 0.58 & $(0.39)$ \\
\hline 1872 & Ward-Devereux (B) & 12 & 0.00 & $(0.13)$ \\
\hline 1872 & Ward-Devereux (M) & 12 & 0.13 & $(0.22)$ \\
\hline 1880 & Taylor/PWT/Maddison & 12 & 0.00 & (0.19) \\
\hline 1884 & Ward-Devereux (B) & 12 & 0.13 & $(0.14)$ \\
\hline 1884 & Ward-Devereux (M) & 12 & 0.02 & $(0.23)$ \\
\hline 1890 & Taylor/PWT/Maddison & 19 & 0.32 & $(0.17)$ \\
\hline 1900 & Taylor/PWT/Maddison & 20 & 0.27 & $(0.16)$ \\
\hline 1905 & Ward-Devereux (B) & 12 & -0.07 & $(0.13)$ \\
\hline 1905 & Ward-Devereux (M) & 12 & 0.00 & $(0.25)$ \\
\hline 1910 & Taylor/PWT/Maddison & 20 & 0.14 & $(0.14)$ \\
\hline 1913 & Maddison & 24 & -0.11 & $(0.11)$ \\
\hline 1920 & Taylor/PWT/Maddison & 19 & 0.41 & $(0.18)$ ** \\
\hline 1930 & Taylor/PWT/Maddison & 20 & 0.33 & $(0.14)^{* *}$ \\
\hline 1930 & Ward-Devereux (B) & 12 & 0.15 & $(0.12)$ \\
\hline 1930 & Ward-Devereux (M) & 12 & 0.28 & $(0.43)$ \\
\hline 1940 & Taylor/PWT/Maddison & 20 & 0.67 & $(0.17)^{* * *}$ \\
\hline 1950 & Taylor/PWT/Maddison & 20 & 0.16 & $(0.18)$ \\
\hline 1950 & Ward-Devereux (B) & 12 & 0.21 & $(0.09) * *$ \\
\hline 1950 & Ward-Devereux (M) & 12 & 0.56 & $(0.25)$ * \\
\hline 1960 & Taylor/PWT/Maddison & 20 & 0.39 & $(0.13) * * *$ \\
\hline 1970 & Taylor/PWT/Maddison & 20 & 0.28 & $(0.14)$ * \\
\hline 1980 & Taylor/PWT/Maddison & 20 & 0.56 & $(0.13) * * *$ \\
\hline 1990 & Taylor/PWT/Maddison & 20 & 0.83 & $(0.11)^{* * *}$ \\
\hline \multicolumn{5}{|c|}{ (c) European Cities 1500-1850 (using real wages) } \\
\hline $1500-49$ & Broadberry/Gupta & 14 & -0.51 & $(0.37)$ \\
\hline 1550-99 & Broadberry/Gupta & 14 & -0.18 & $(0.41)$ \\
\hline $1600-49$ & Broadberry/Gupta & 14 & -0.47 & $(0.33)$ \\
\hline 1650-99 & Broadberry/Gupta & 14 & -0.07 & $(0.54)$ \\
\hline $1700-49$ & Broadberry/Gupta & 14 & 0.22 & $(0.30)$ \\
\hline 1750-99 & Broadberry/Gupta & 14 & -0.07 & $(0.28)$ \\
\hline $1800-49$ & Broadberry/Gupta & 14 & 0.14 & $(0.24)$ \\
\hline
\end{tabular}

Notes: (a) using GDP deflator; (b) using CPI or, if unavailable, GDP deflator.

Significance levels: ${ }^{*} 10 \%,{ }^{* *} 5 \%,{ }^{* *} 1 \%$. 
Table 2: The Balassa-Samuelson Effect Since 1870 in Short Panels

Panel regression of the log relative price level on log relative real income per capita

\begin{tabular}{|c|c|c|c|c|c|c|}
\hline Year(s) & Sources & $N$ & $\beta$ & s.e. & $\rho$ & $H$ \\
\hline \multicolumn{7}{|c|}{ (a) Postwar Sample 1950-2000 } \\
\hline $1950-9$ & PWT & 649 & 0.12 & $(0.03)^{* \star *}$ & 0.87 & 4.91 \\
\hline 1960-9 & PWT & 1089 & 0.14 & $(0.02) * * *$ & 0.89 & 5.78 \\
\hline 1970-9 & PWT & 1127 & 0.15 & $(0.03) * * *$ & 0.88 & 5.35 \\
\hline 1980-9 & PWT & 1188 & 0.28 & $(0.04)^{* \star *}$ & 0.82 & 3.47 \\
\hline 1990-9 & PWT & 1253 & 0.32 & $(0.03)^{* * *}$ & 0.84 & 4.07 \\
\hline \multicolumn{7}{|c|}{ (b) Historical Sample 1870-1990 ( $\mathrm{N}=20)$} \\
\hline $1880-9$ & Taylor/PWT/Maddison & 140 & 0.20 & $(0.12)$ * & 0.94 & 12.09 \\
\hline 1890-9 & Taylor/PWT/Maddison & 164 & 0.05 & $(0.11)$ & 0.93 & 9.17 \\
\hline $1900-9$ & Taylor/PWT/Maddison & 200 & 0.13 & $(0.06)$ ** & 0.91 & 7.48 \\
\hline $1910-9$ & Taylor/PWT/Maddison & 192 & -0.18 & $(0.15)$ & 0.84 & 3.88 \\
\hline 1920-9 & Taylor/PWT/Maddison & 199 & 0.24 & $(0.09)^{* * *}$ & 0.90 & 6.76 \\
\hline $1930-9$ & Taylor/PWT/Maddison & 199 & 0.36 & $(0.12)^{* * *}$ & 0.81 & 3.30 \\
\hline $1940-9$ & Taylor/PWT/Maddison & 193 & -0.07 & $(0.10)$ & 0.88 & 5.21 \\
\hline 1950-9 & Taylor/PWT/Maddison & 200 & 0.11 & $(0.14)$ & 0.91 & 7.01 \\
\hline $1960-9$ & Taylor/PWT/Maddison & 200 & 0.29 & $(0.11)^{* * *}$ & 0.91 & 7.11 \\
\hline $1970-9$ & Taylor/PWT/Maddison & 200 & 0.42 & $(0.12)^{* * *}$ & 0.86 & 4.52 \\
\hline 1980-9 & Taylor/PWT/Maddison & 200 & 1.06 & $(0.19)^{* \star *}$ & 0.73 & 2.24 \\
\hline $1990-9$ & Taylor/PWT/Maddison & 104 & 0.68 & $3(0.11)^{* * *}$ & 0.68 & 1.78 \\
\hline
\end{tabular}

Notes: Standard errors are corrected for errors with a common AR1 parameter and cross-sectional correlation. 
Table 3.

Experiment 1: Effects of Homogeneous Productivity Shock

\begin{tabular}{c|ccccc}
\hline Years & $y / y^{*}$ & $p / p^{*}$ & $\mathrm{BS}=\ln \left(p / p^{*}\right) / \mathrm{n}\left(y / y^{*}\right)$ & traded & traded $^{*}$ \\
\hline 0 & 1.00 & 1.00 & -- & 5 & 5 \\
10 & 1.09 & 0.98 & -0.25 & 5 & 5 \\
20 & 1.12 & 0.93 & -0.64 & 4 & 5 \\
30 & 1.23 & 0.91 & -0.49 & 4 & 5 \\
40 & 1.34 & 0.88 & -0.42 & 4 & 5 \\
50 & 1.46 & 0.86 & -0.39 & 4 & 5 \\
60 & 1.51 & 0.84 & -0.42 & 4 & 6 \\
70 & 1.65 & 0.82 & -0.39 & 4 & 6 \\
80 & 1.77 & 0.75 & -0.50 & 3 & 5 \\
90 & 1.84 & 0.73 & -0.51 & 3 & 6 \\
100 & 2.00 & 0.71 & -0.48 & 3 & 6 \\
\hline
\end{tabular}

Parameter settings: $\mu_{\alpha 1}=0.015, \mu_{T 0}=\mu_{T 1}=\mu_{\alpha 0}=0, \mu_{T 0}^{*}=\mu_{T 1}^{*}=\mu_{\alpha 0}^{*}=\mu_{\alpha_{1}}^{*}=0$, $f_{X}=0.12, \lambda=\lambda^{*}=1, \sigma=\sigma^{*}=0.01$

Table 4.

Experiment 2: Effects of Heterogeneous (Fréchet) Productivity Shock

\begin{tabular}{|c|c|c|c|c|c|}
\hline Years & $y / y^{*}$ & $p / p^{*}$ & $\mathrm{BS}=\ln \left(p / p^{*}\right) / \ln \left(y / y^{*}\right)$ & traded & traded $^{*}$ \\
\hline 0 & 1.00 & 1.00 & -- & 5 & 5 \\
\hline 10 & 1.06 & 1.02 & 0.31 & 4 & 4 \\
\hline 20 & 1.07 & 1.01 & 0.20 & 4 & 5 \\
\hline 30 & 1.09 & 1.02 & 0.23 & 3 & 5 \\
\hline 40 & 1.13 & 1.03 & 0.27 & 2 & 5 \\
\hline 50 & 1.26 & 1.08 & 0.34 & 2 & 5 \\
\hline 60 & 1.35 & 1.12 & 0.38 & 2 & 6 \\
\hline 70 & 1.46 & 1.15 & 0.38 & 1 & 6 \\
\hline 80 & 1.60 & 1.22 & 0.42 & 1 & 7 \\
\hline 90 & 1.84 & 1.28 & 0.40 & 1 & 7 \\
\hline 100 & 2.03 & 1.35 & 0.42 & 1 & 8 \\
\hline
\end{tabular}

Parameter settings: $\mu_{T 1}=0.165, \mu_{T 0}=\mu_{\alpha 0}=\mu_{\alpha 1}=0, \mu_{T 0}^{*}=\mu_{T 1}^{*}=\mu_{\alpha 0}^{*}=\mu_{\alpha 1}^{*}=0$, $f_{X}=0.12, \lambda=\lambda^{*}=1, \sigma=\sigma^{*}=0.01$ 
Table 5.

Experiment 3: Effects of Homogeneous Productivity Shock, with Initial Heterogeneous (Fréchet) Distribution

\begin{tabular}{c|ccccc}
\hline Years & $y / y^{*}$ & $p / p^{*}$ & $\mathrm{BS}=\ln \left(p / p^{*}\right) / \ln \left(y / y^{*}\right)$ & traded & traded $^{*}$ \\
\hline 0 & 1.00 & 1.00 & -- & 5 & 5 \\
10 & 1.07 & 1.04 & 0.59 & 5 & 6 \\
20 & 1.16 & 1.04 & 0.24 & 5 & 6 \\
30 & 1.24 & 1.08 & 0.36 & 4 & 6 \\
40 & 1.33 & 1.13 & 0.41 & 4 & 7 \\
50 & 1.44 & 1.12 & 0.31 & 4 & 7 \\
60 & 1.54 & 1.16 & 0.35 & 4 & 8 \\
70 & 1.65 & 1.21 & 0.38 & 3 & 8 \\
80 & 1.77 & 1.26 & 0.40 & 3 & 9 \\
90 & 1.92 & 1.25 & 0.35 & 3 & 9 \\
100 & 2.07 & 1.25 & 0.30 & 3 & 9 \\
\hline
\end{tabular}

Parameter settings: $\mu_{\alpha 1}=0.015, \mu_{T 0}=\mu_{T 0}^{*}=0.165 * 100, \mu_{T 1}=\mu_{\alpha 0}=0$, $\mu_{T 1}^{*}=\mu_{\alpha 0}^{*}=\mu_{\alpha 1}^{*}=0, f_{X}=0.034, \lambda=\lambda^{*}=1, \sigma=\sigma^{*}=0.01$

Table 6.

Experiment 4: Effects of Homogeneous Shock, followed by Heterogeneous (Fréchet) Shock

\begin{tabular}{c|ccccc}
\hline Years & $y / y^{*}$ & $p / p^{*}$ & $\mathrm{BS}=\ln \left(p / p^{*}\right) / \ln \left(y / y^{*}\right)$ & traded & traded $^{*}$ \\
\hline 0 & 1.08 & 0.98 & -- & 5 & 5 \\
10 & 1.08 & 0.97 & -0.42 & 4 & 5 \\
20 & 1.14 & 0.98 & -0.14 & 3 & 4 \\
30 & 1.16 & 0.99 & -0.07 & 3 & 5 \\
40 & 1.19 & 1.00 & -0.02 & 2 & 5 \\
50 & 1.32 & 1.04 & 0.16 & 2 & 5 \\
60 & 1.40 & 1.08 & 0.24 & 2 & 6 \\
70 & 1.50 & 1.11 & 0.27 & 1 & 6 \\
80 & 1.64 & 1.18 & 0.34 & 1 & 7 \\
90 & 1.87 & 1.24 & 0.35 & 1 & 7 \\
100 & 2.06 & 1.32 & 0.38 & 1 & 8 \\
\hline
\end{tabular}

Parameter settings: $\mu_{T 1}=0.165, \mu_{\alpha 0}=0.015 * 10, \mu_{T 0}=\mu_{\alpha_{1}}=0$, $\mu_{T 0}^{*}=\mu_{T 1}^{*}=\mu_{\alpha 0}^{*}=\mu_{\alpha 1}^{*}=0, f_{X}=0.12, \lambda=\lambda^{*}=1, \sigma=\sigma^{*}=0.01$ 
Table 7.

Experiment 5: Effects of Combined Homogeneous and Heterogeneous (Fréchet) Productivity Shock

\begin{tabular}{c|ccccc}
\hline Years & $y / y^{*}$ & $p / p^{*}$ & $\mathrm{BS}=\log \left(p / p^{*}\right) / \log \left(y / y^{*}\right)$ & traded & traded $^{*}$ \\
\hline 0 & 1.00 & 1.00 & 0.31 & 5 & 5 \\
10 & 1.02 & 0.98 & -0.78 & 4 & 5 \\
20 & 1.11 & 1.00 & -0.04 & 4 & 5 \\
30 & 1.15 & 0.99 & -0.07 & 3 & 5 \\
40 & 1.21 & 0.99 & -0.08 & 2 & 5 \\
50 & 1.36 & 1.02 & 0.07 & 2 & 5 \\
60 & 1.47 & 1.05 & 0.13 & 2 & 6 \\
70 & 1.59 & 1.06 & 0.13 & 1 & 6 \\
80 & 1.76 & 1.12 & 0.20 & 1 & 7 \\
90 & 1.96 & 1.19 & 0.26 & 1 & 8 \\
100 & 2.26 & 1.24 & 0.27 & 1 & 8 \\
\hline
\end{tabular}

Parameter settings: $\mu_{T 1}=0.8 \cdot 0.165 \mu_{\alpha_{1}}=0.3 \cdot 0.015, \mu_{T 0}=\mu_{\alpha_{0}}=0$, $\mu_{T 0}^{*}=\mu_{T 1}^{*}=\mu_{\alpha 0}^{*}=\mu_{\alpha 1}^{*}=0, f_{X}=0.12, \lambda=\lambda^{*}=1, \sigma=\sigma^{*}=0.01$

Table 8.

Experiment 6: Effects of Heterogeneous (Fréchet) Shock to Emerging Sectors Only

\begin{tabular}{c|ccccc}
\hline Years & $y / y^{*}$ & $p / p^{*}$ & $\mathrm{BS}=\ln \left(p / p^{*}\right) / \ln \left(y / y^{*}\right)$ & traded & traded $^{*}$ \\
\hline 0 & 1.00 & 1.00 & -- & 5 & 5 \\
10 & 1.02 & 0.99 & -0.33 & 5 & 5 \\
20 & 1.06 & 0.99 & -0.10 & 5 & 5 \\
30 & 1.11 & 1.00 & -0.01 & 5 & 5 \\
40 & 1.15 & 1.03 & 0.20 & 4 & 5 \\
50 & 1.20 & 1.07 & 0.34 & 4 & 6 \\
60 & 1.29 & 1.11 & 0.41 & 3 & 6 \\
70 & 1.41 & 1.16 & 0.44 & 2 & 6 \\
80 & 1.56 & 1.23 & 0.47 & 2 & 7 \\
90 & 1.72 & 1.34 & 0.54 & 2 & 9 \\
100 & 1.95 & 1.41 & 0.51 & 1 & 9 \\
\hline
\end{tabular}

Parameter settings: Emerging sectors ( $\mathrm{i}=1-5): \mu_{T 0}=\mu_{T 0}^{*}=0, \mu_{T 1}=0.039$

Mature sectors (i=6-10): $\mu_{T 0}=\mu_{T 0}^{*}=0.165 * 100, \mu_{T 1}=0$

All sectors: $\mu_{\alpha 0}=\mu_{\alpha 1}=\mu_{T 1}^{*}=\mu_{\alpha 0}^{*}=\mu_{\alpha 1}^{*}=0, f_{X}=0.077, \lambda=\lambda^{*}=1, \sigma=\sigma^{*}=0.01$ 
Table 9.

Sectoral TFP in the British Industrial Revolution, 1780-1860

\begin{tabular}{l|cccc}
\multicolumn{2}{c}{} & Output share & \multicolumn{3}{c}{ TFP growth rate (\% per annum) } \\
& & McCloskey & Crafts & Harley \\
\hline Cotton & 0.05 & 2.6 & 2.6 & 1.9 \\
Worsteds & 0.02 & 1.8 & 1.8 & 1.3 \\
Woolens & 0.02 & 0.9 & 0.9 & 0.6 \\
Iron & 0.01 & 0.9 & 0.9 & 0.9 \\
Canals and railroads & 0.05 & 1.3 & 1.3 & 1.3 \\
Shipping & 0.04 & 2.3 & 2.3 & 0.5 \\
Agriculture & 0.19 & 0.45 & 0.45 & 0.7 \\
Others & 0.60 & 0.65 & 0.08 & 0.02 \\
\hline
\end{tabular}

Sources: McCloskey (1981), Crafts (1985), Harley (1993). 
Table 10.

Sources of Productivity Growth in the United States, 1958-96

\begin{tabular}{|c|c|c|c|}
\hline & $\begin{array}{l}\text { TFP growth } \\
\text { (a) }\end{array}$ & $\begin{array}{c}\text { Domar weight } \\
\text { (b) }\end{array}$ & $\begin{array}{l}\text { Contribution } \\
\text { (a) } \times \text { (b) }\end{array}$ \\
\hline Goverment Enterprises & -0.516 & 0.022 & -0.011 \\
\hline Printing and Publishing & -0.445 & 0.024 & -0.011 \\
\hline Construction & -0.442 & 0.113 & -0.050 \\
\hline Petroleum and Gas & -0.437 & 0.022 & -0.010 \\
\hline Gas Utilities & -0.241 & 0.016 & -0.004 \\
\hline Tobacco Products & -0.200 & 0.004 & -0.001 \\
\hline Services & -0.190 & 0.208 & -0.040 \\
\hline FIRE & -0.176 & 0.131 & -0.023 \\
\hline Lumber and Wood & -0.020 & 0.015 & 0.000 \\
\hline Private Households & 0.000 & 0.137 & 0.000 \\
\hline General Government & 0,000 & 0.131 & 0.000 \\
\hline Other Transportation Equipment & 0.183 & 0.027 & 0.005 \\
\hline Primary Metals & 0.224 & 0.040 & 0.009 \\
\hline Motor Vehicles & 0.242 & 0.043 & 0.010 \\
\hline Leather Products & 0.285 & 0.004 & 0.001 \\
\hline Petroleum Refining & 0.327 & 0.033 & 0.011 \\
\hline Stone, Clay, and Glass & 0.414 & 0.014 & 0.006 \\
\hline Paper Products & 0.416 & 0.022 & 0.009 \\
\hline Metal Mining & 0.440 & 0.003 & 0.001 \\
\hline Nonmetallic Mining & 0.461 & 0.003 & 0.001 \\
\hline Electric Utilities & 0.515 & 0.026 & 0.013 \\
\hline Food Products & 0.535 & 0.076 & 0.041 \\
\hline Furniture and Fixtures & 0.562 & 0.007 & 0.004 \\
\hline Chemical Products & 0.584 & 0.048 & 0.028 \\
\hline Fabricated Metals & 0.648 & 0.035 & 0.023 \\
\hline Apparel and Textiles & 0.804 & 0.022 & 0.018 \\
\hline Miscellaneous Manufacturing & 0.821 & 0.008 & 0.007 \\
\hline Coal Mining & 0.837 & 0.005 & 0.004 \\
\hline Transport and Warehouse & 0.863 & 0.061 & 0.053 \\
\hline Communications & 0.882 & 0.033 & 0.029 \\
\hline Trade & 0.979 & 0.195 & 0.191 \\
\hline Rubber and Plastic & 1.043 & 0.016 & 0.017 \\
\hline Instruments & 1.121 & 0.017 & 0.019 \\
\hline Agriculture & 1.169 & 0.062 & 0.072 \\
\hline Textile Mill Products & 1.23 & 0.013 & 0.016 \\
\hline Industrial Machinery and & & & \\
\hline Equipment & 1.461 & 0.048 & 0.070 \\
\hline Electronic and Electric Equipment & 1.975 & 0.036 & 0.071 \\
\hline
\end{tabular}

Source: Jorgenson and Stiroh (2000). 

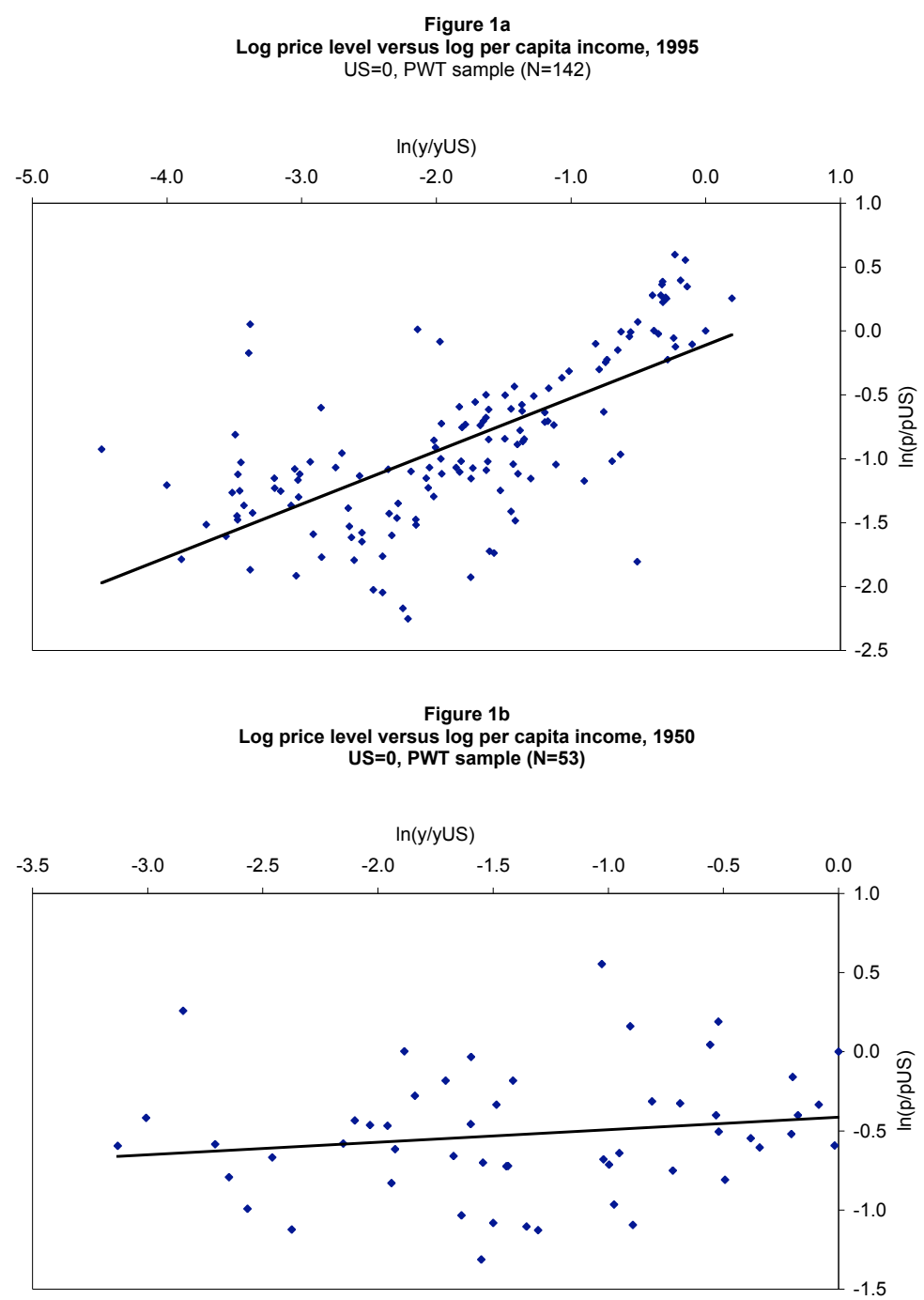

Figure 1c

Log price level versus log per capita income, 1913, US $=0$, Maddison sample $(\mathrm{N}=24)$

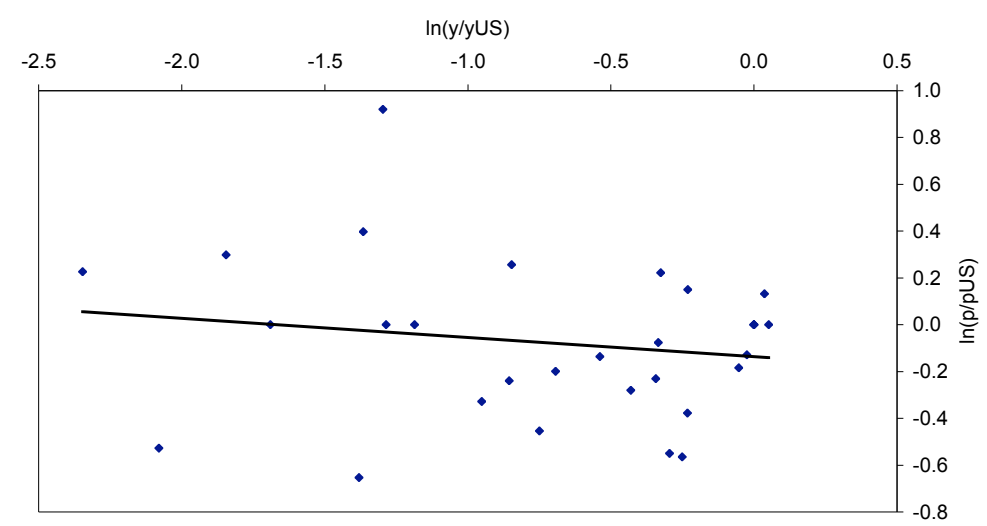

Notes and Sources: Scatter plots of log price level versus log per capita income. Various samples. See text. 

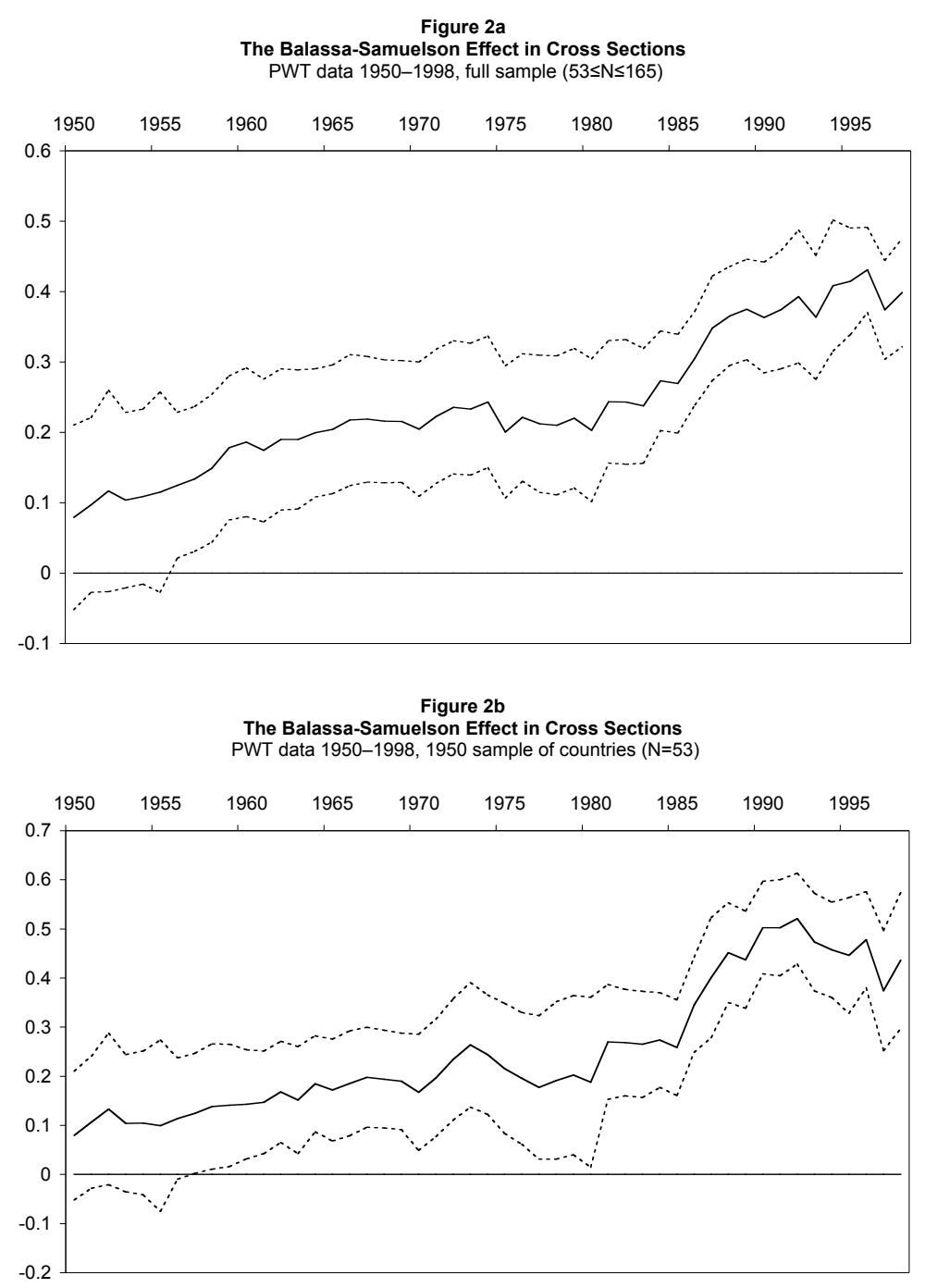

The Balassa-Samuelson Effect in Cross Sections Taylor/Maddison data 1870-1994 ( $\mathrm{N}=20)$

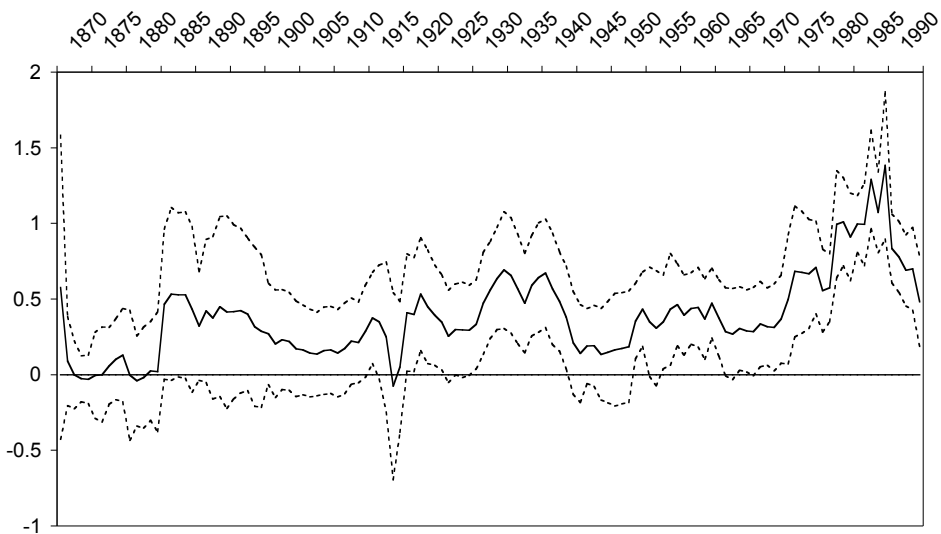

Notes and Sources: Coefficient from cross-country regression of log price level on log per capita income (solid line) with $95 \%$ confidence interval (dashed lines). Various samples. See text. 
Fig. 3a. Experiment 1: Homogeneous Productivity Shock

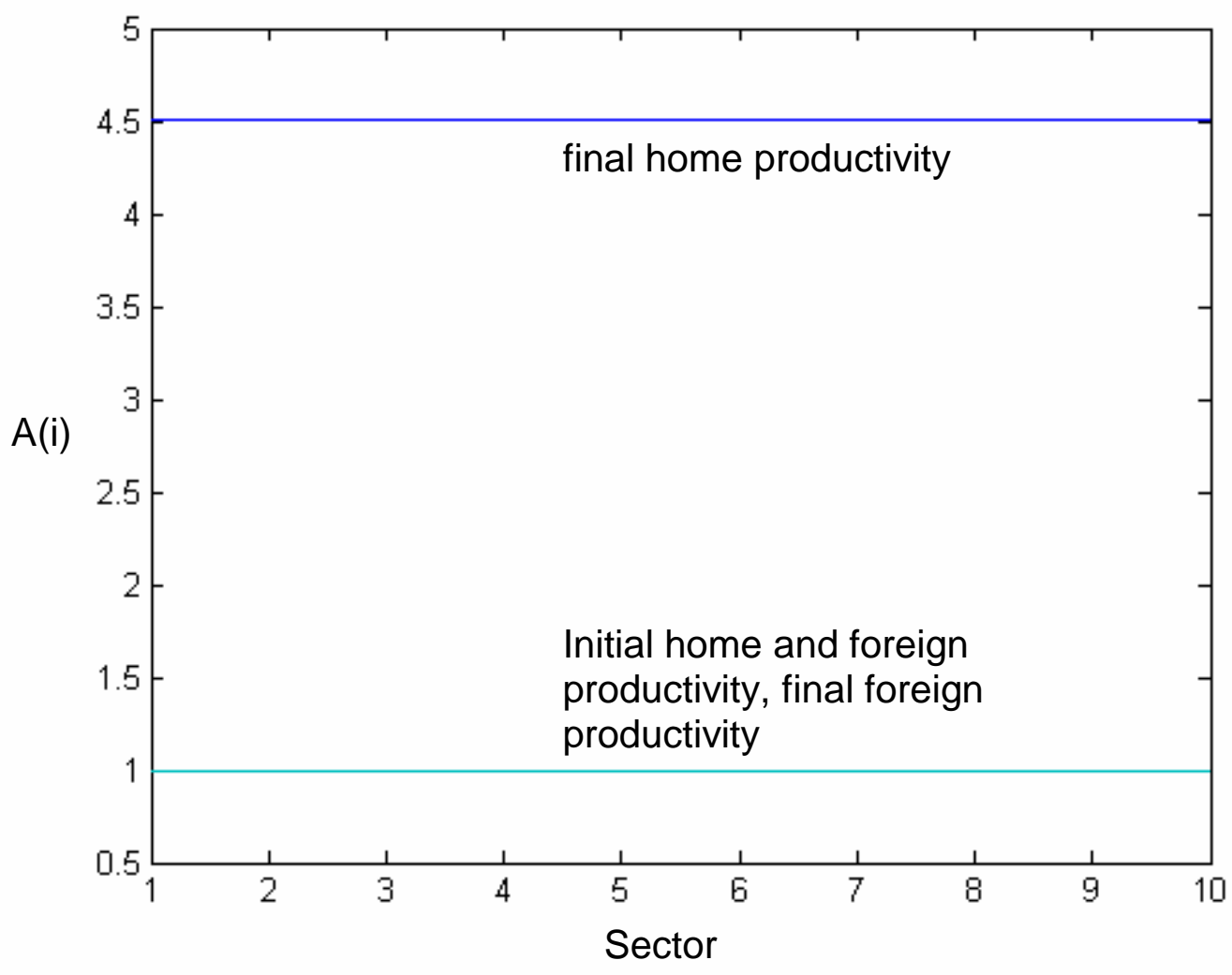

Figure 3b. Effects of Homogeneous Productivity Shock

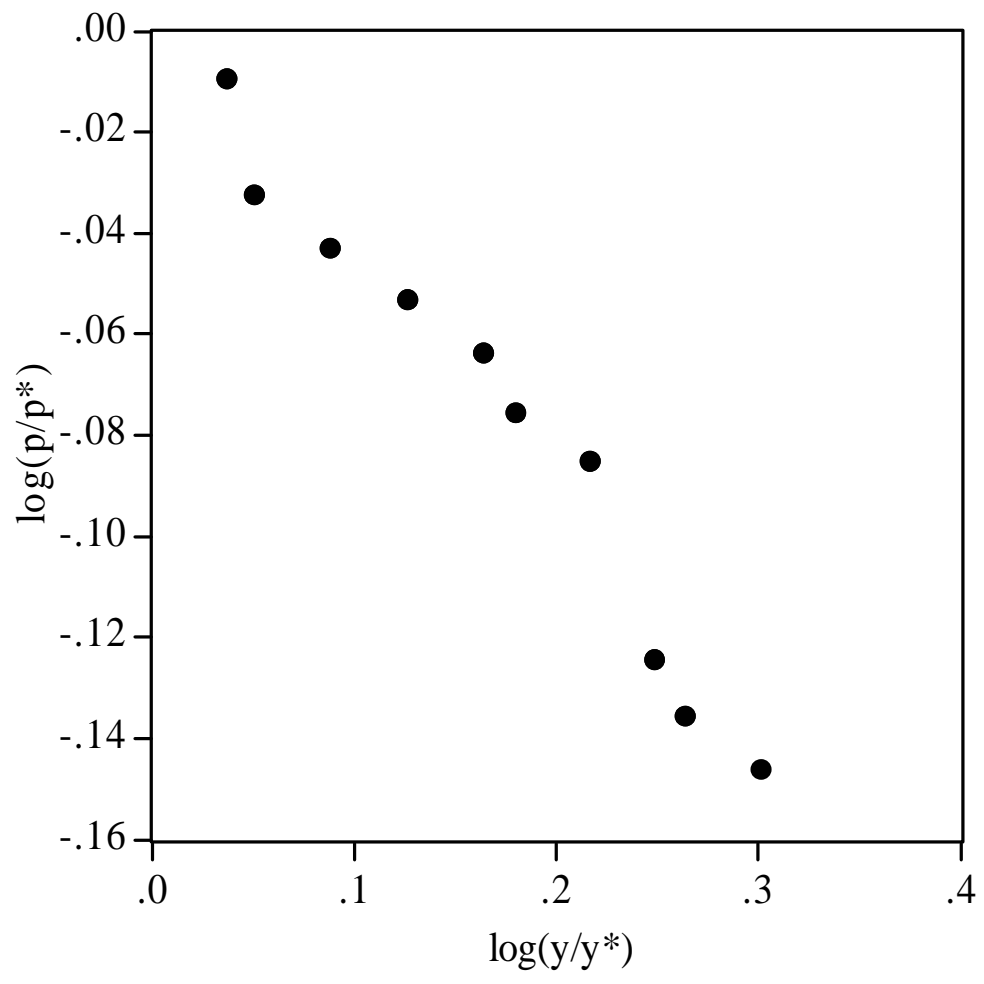


Fig. 4a. Experiment 2: Heterogeneous (Fréchet) Productivity Shock

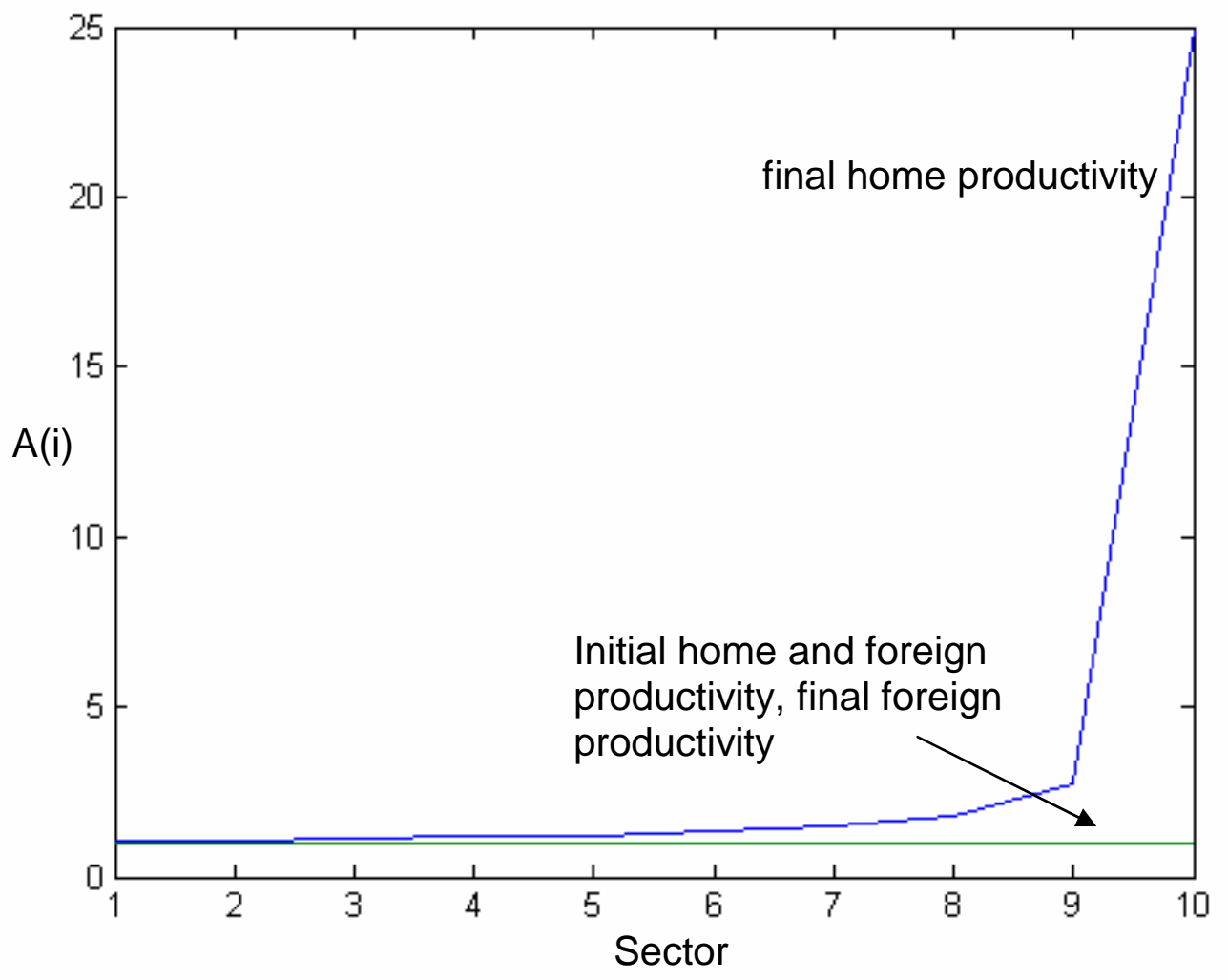

Fig. 4b. Effects of Heterogeneous Productivity Shock

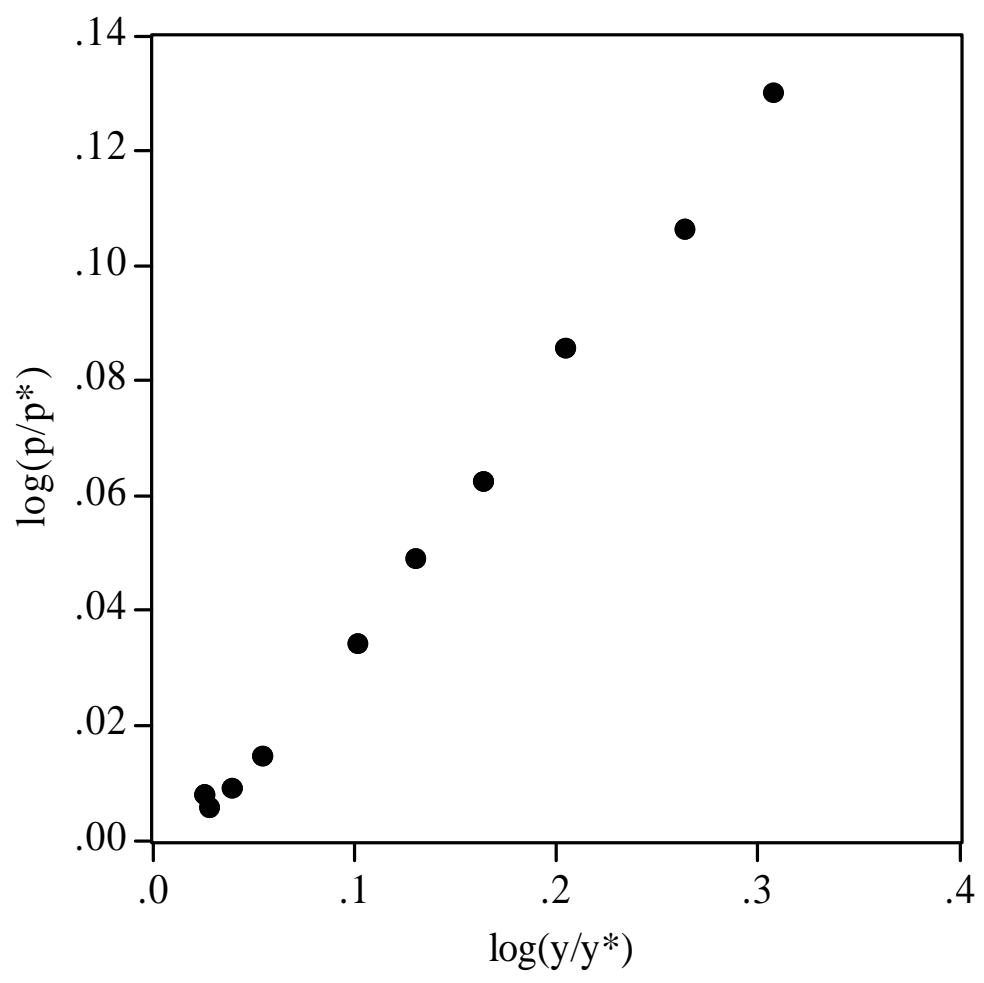


Fig. 5a. Experiment 3: Homogeneous Productivity Shock, with Initial Heterogeneous (Fréchet) Distribution

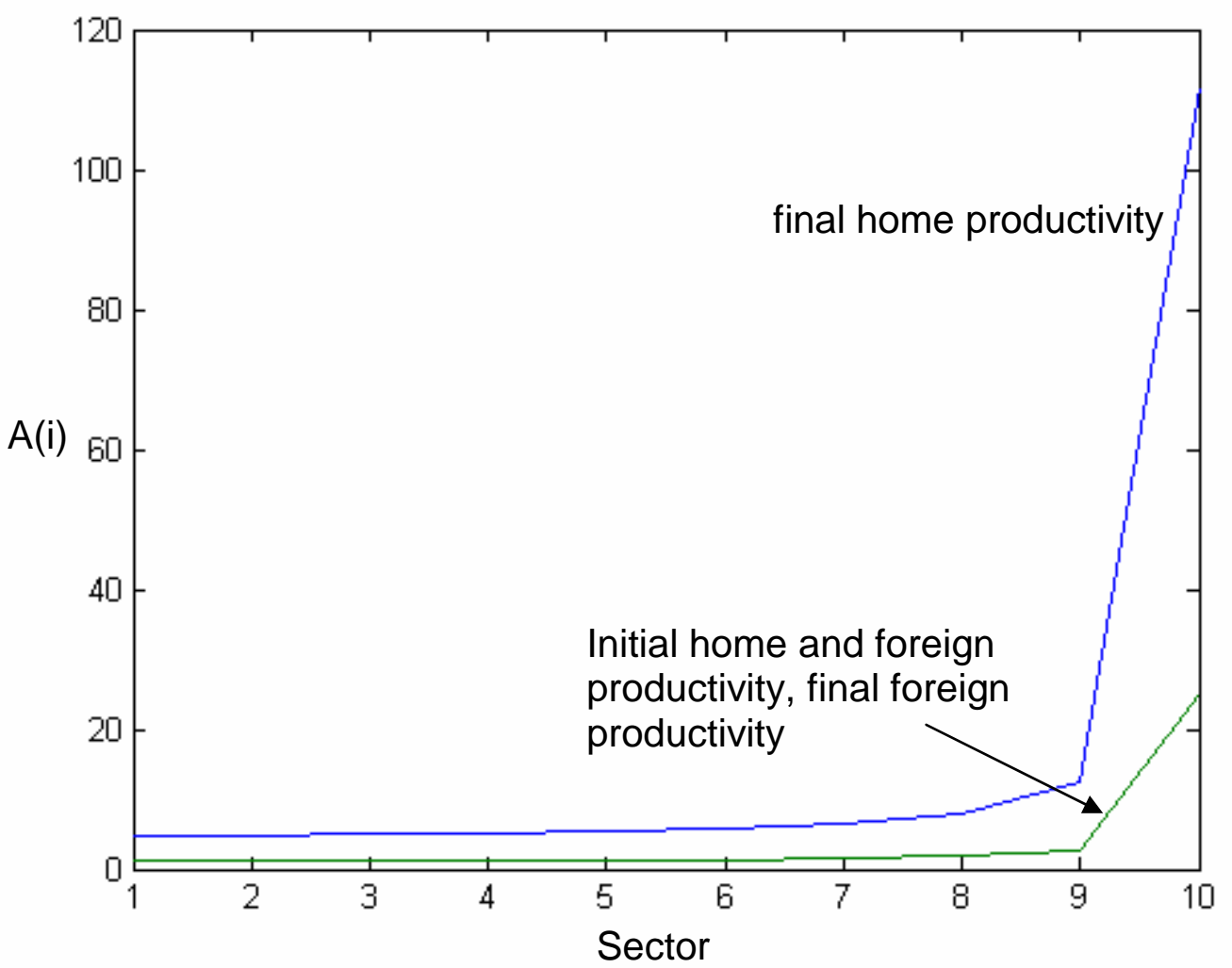

Fig. 5b. Effects of Homogeneous Shock, with Initial Heterogeneous (Fréchet) Distribution

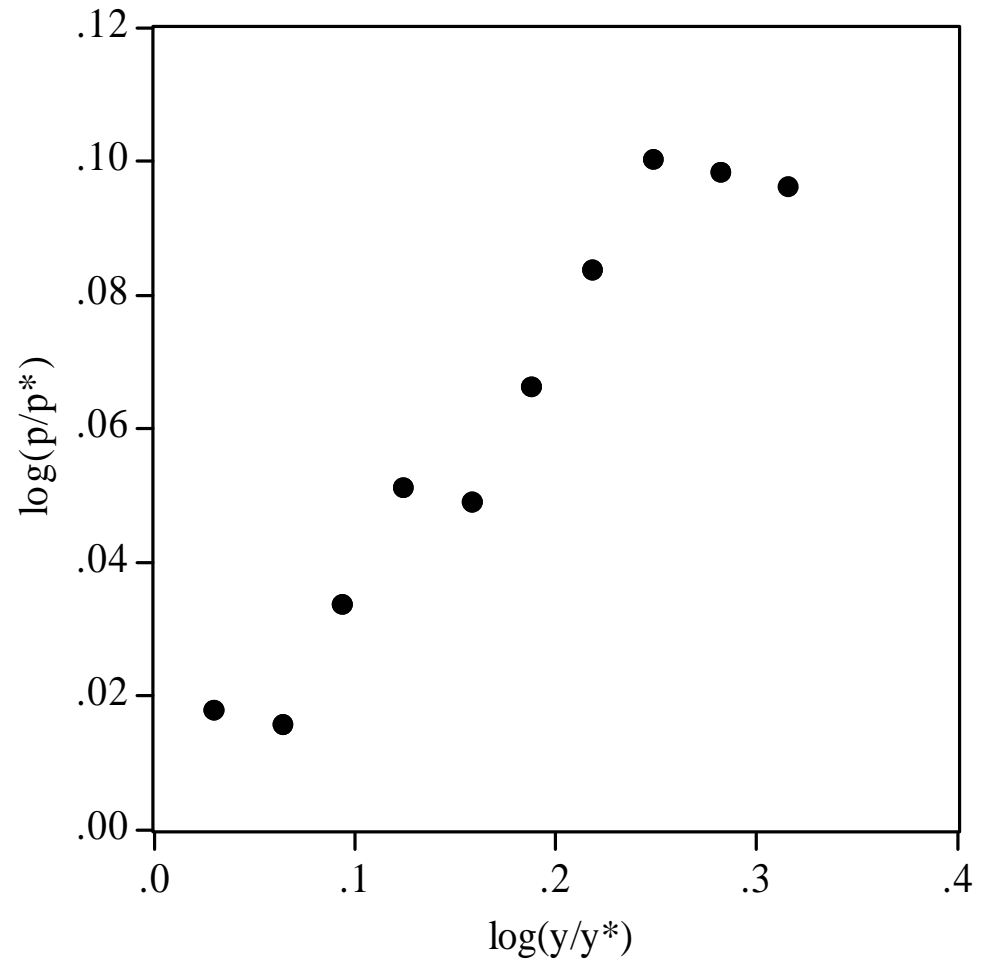


Fig. 6a. Experiment 4: Homogeneous Productivity Shock, followed by Heterogeneous (Fréchet) Shock

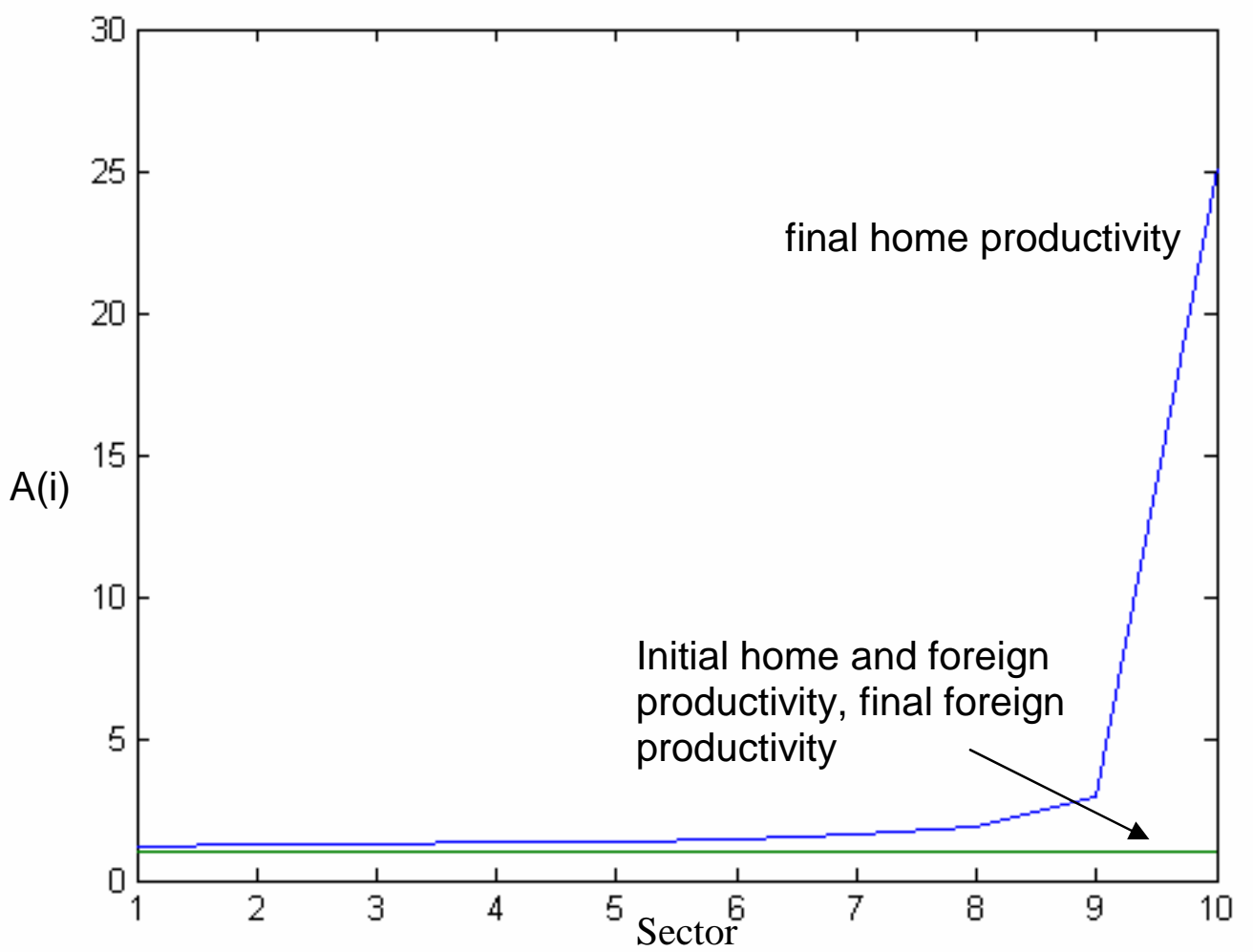

Fig. 6b. Effects of Homogeneous Shock, followed by Heterogeneous (Fréchet) Shock

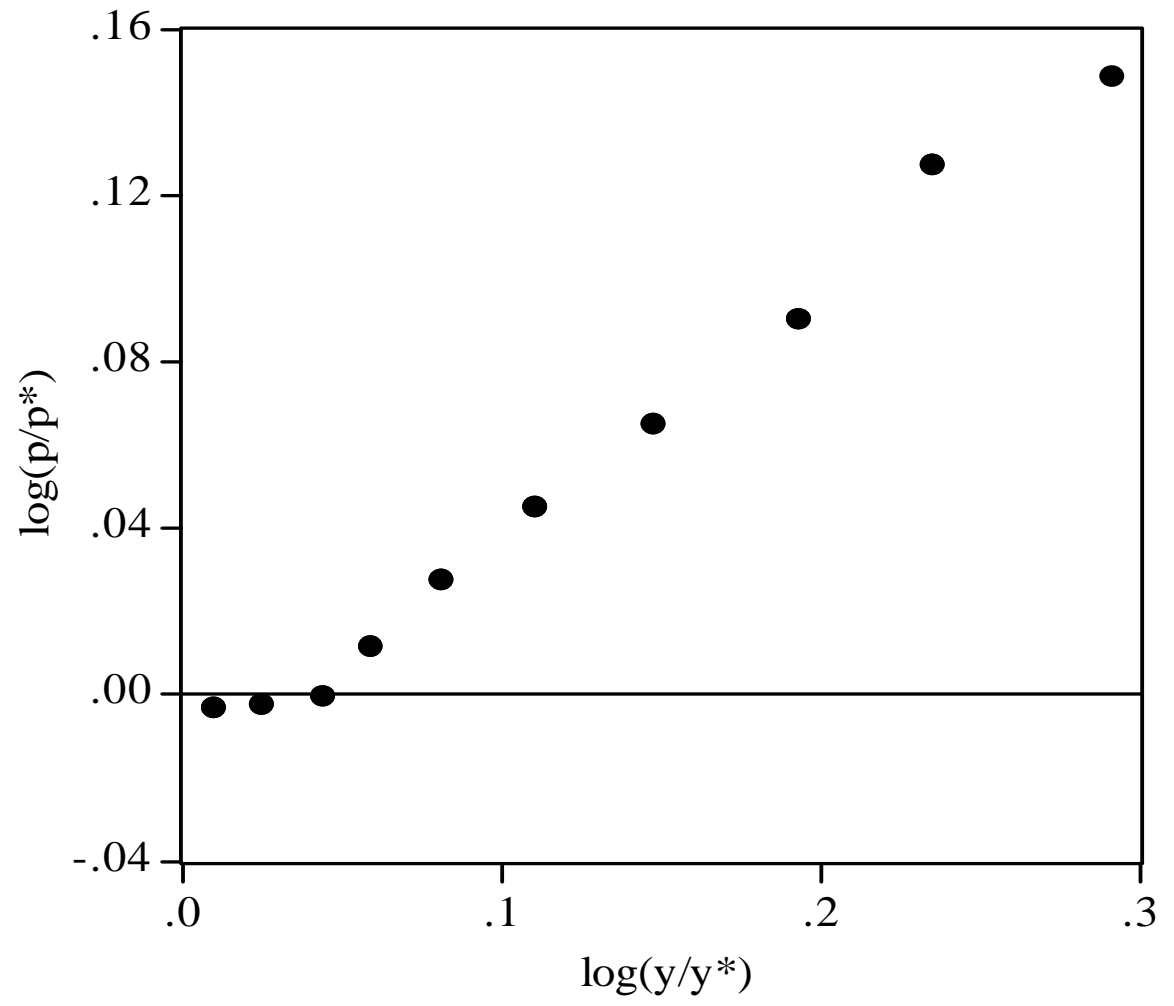


Fig. 7a. Experiment 5: Combined Homogeneous and Heterogeneous (Fréchet) Productivity Shocks

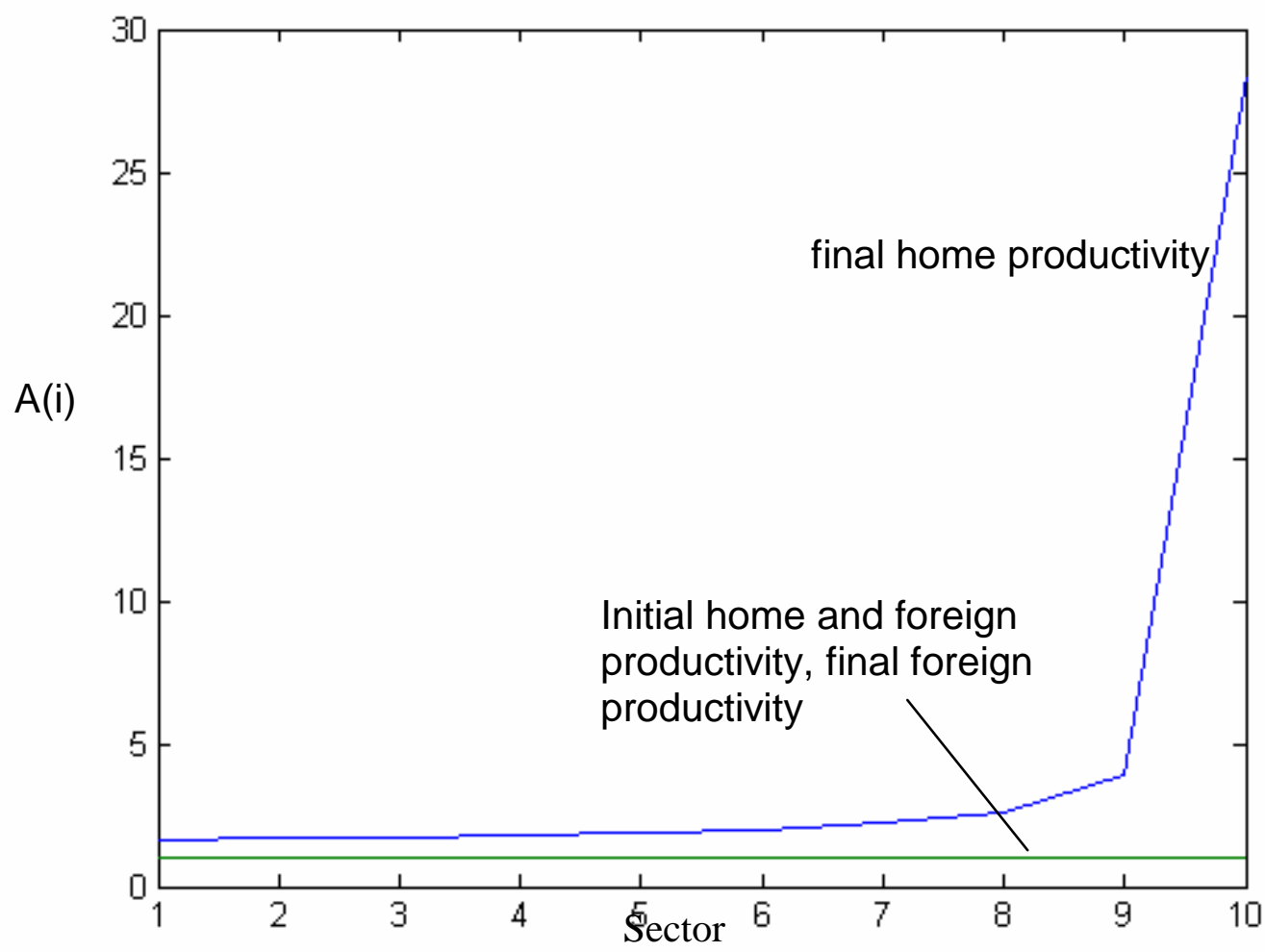

Fig. 7b. Effects of Combined Homogeneous and Heterogenous (Fréchet) Shocks

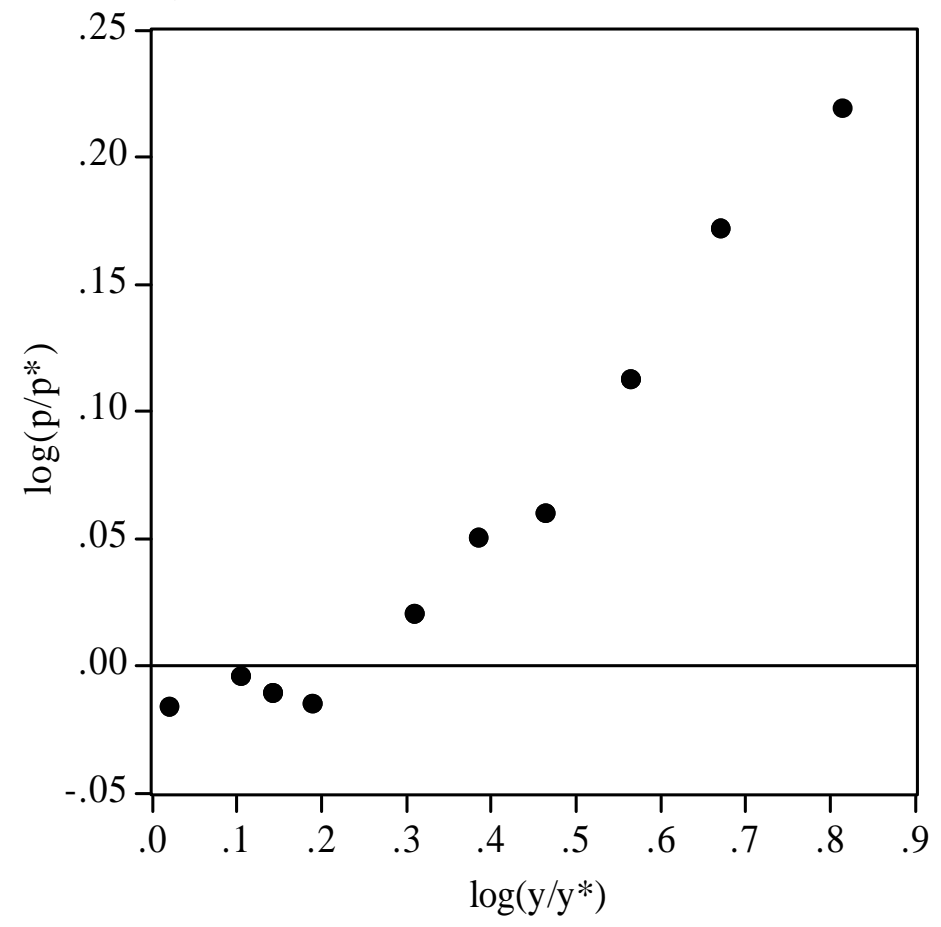


Fig. 8a. Experiment 6: Heterogeneous (Fréchet) Shock to Emerging Sectors Only

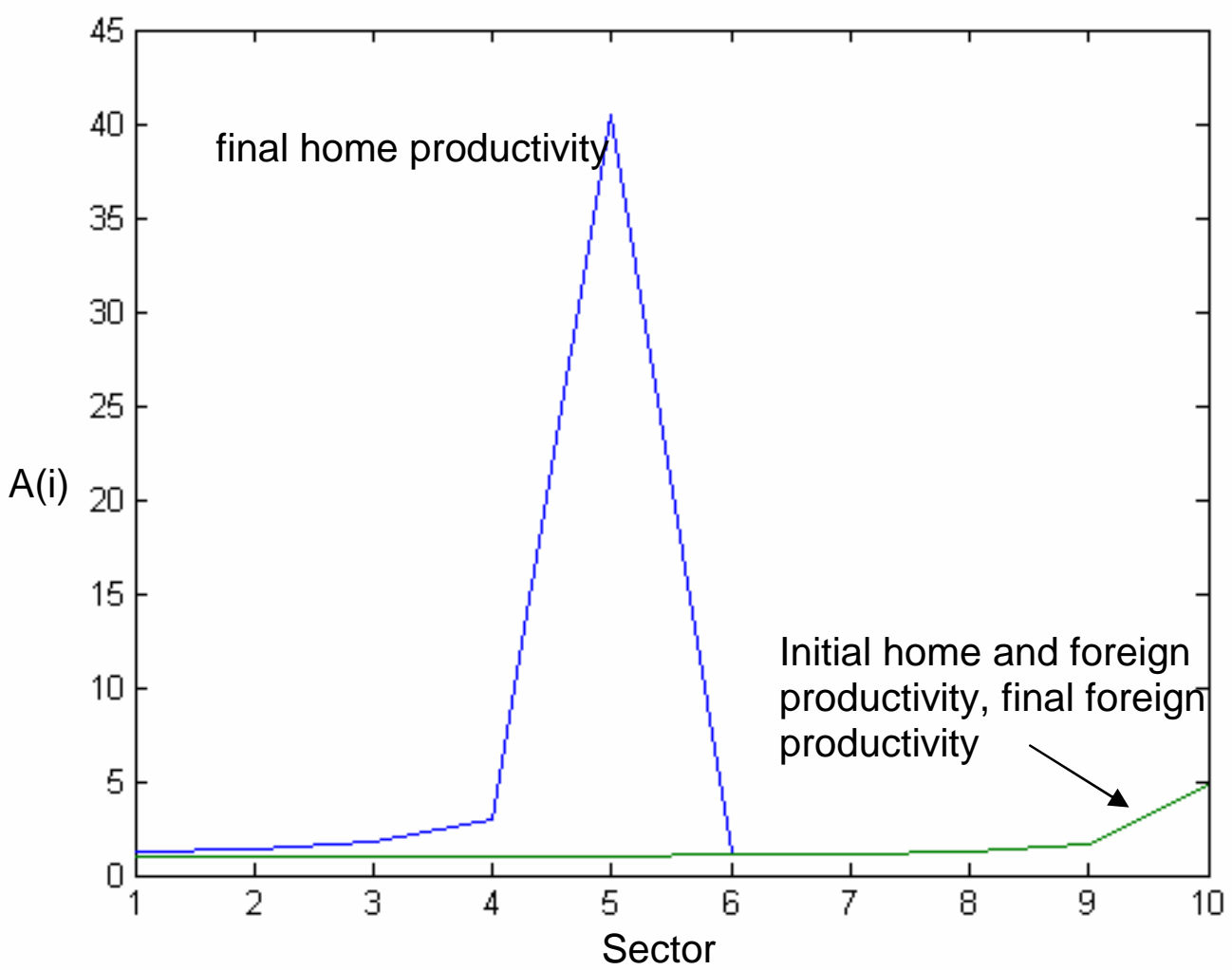

Fig. 8b. Effects of Heterogeneous (Fréchet) Shock to Emerging Sectors Only

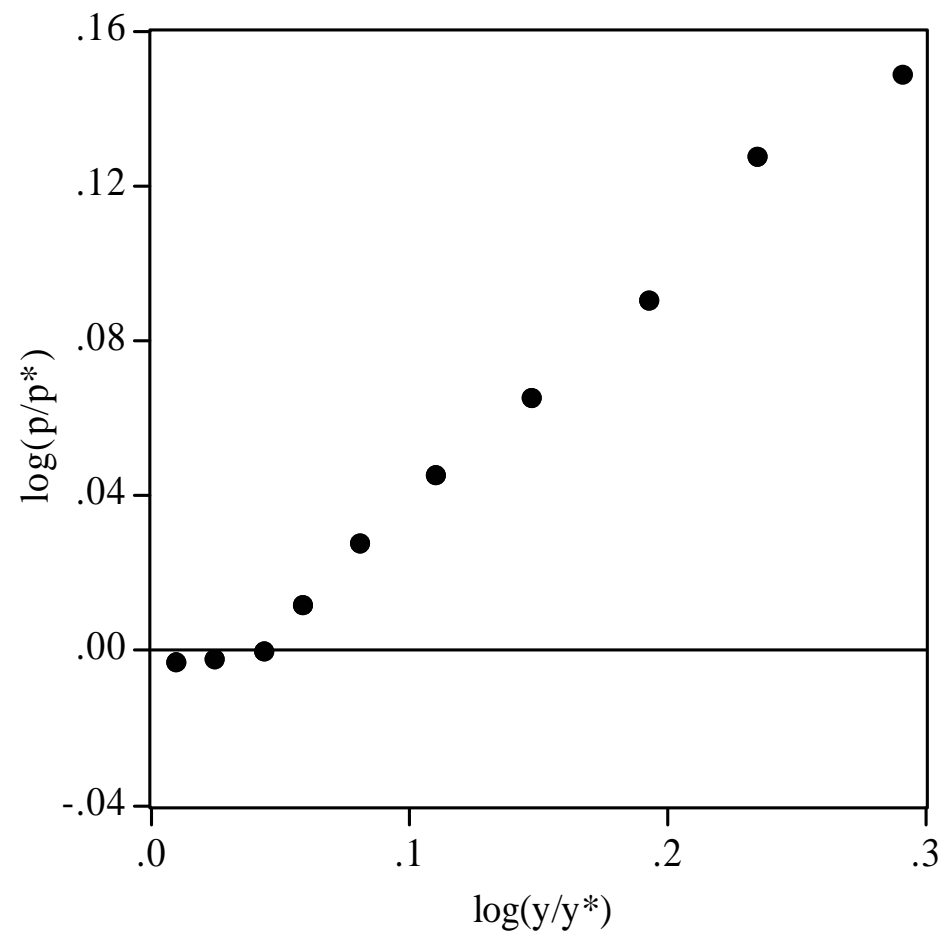


Figure 9

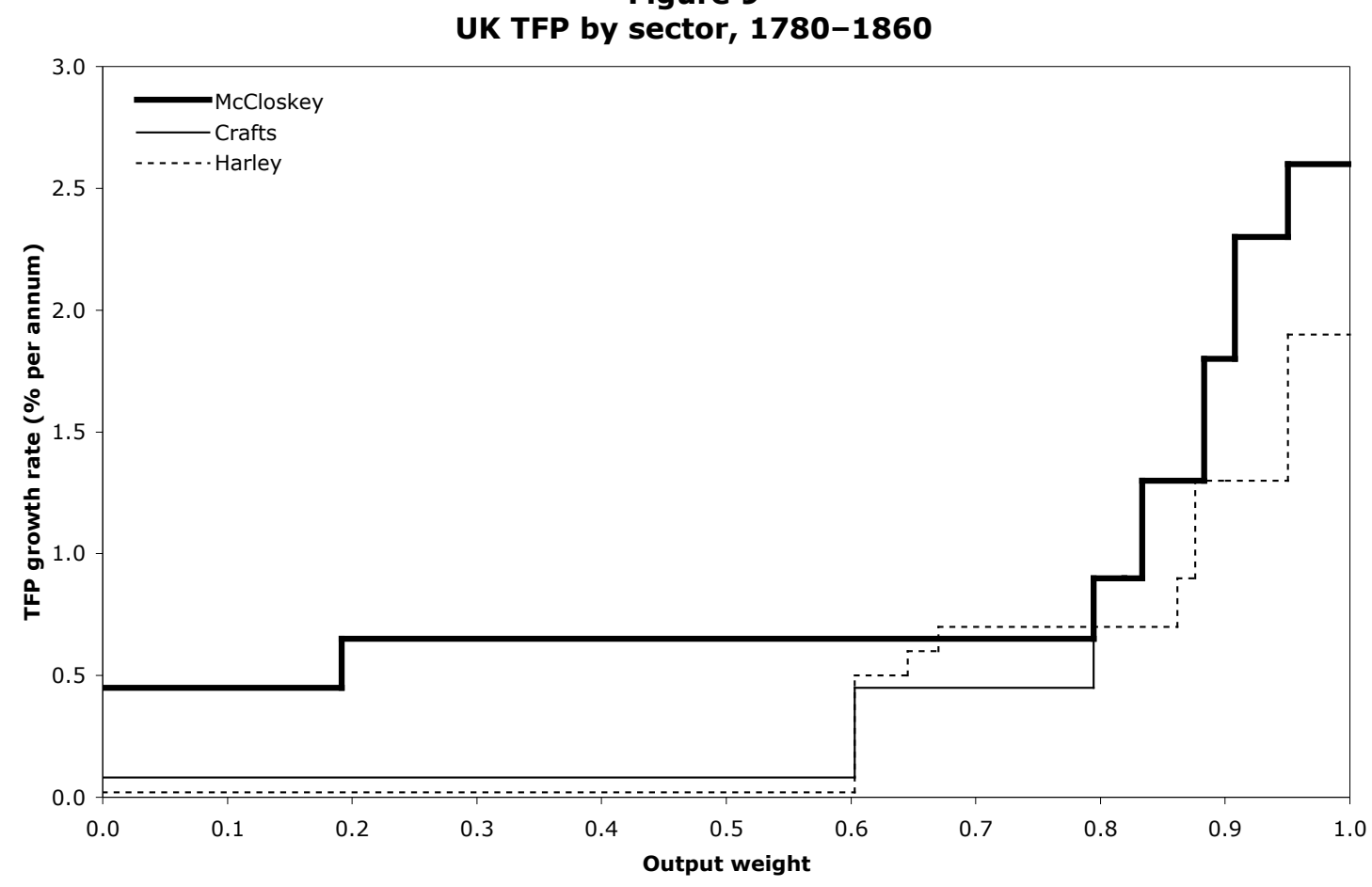

Sources: See Table 9.

Figure 10

Sources of Productivity Growth in the United States, 1958-96

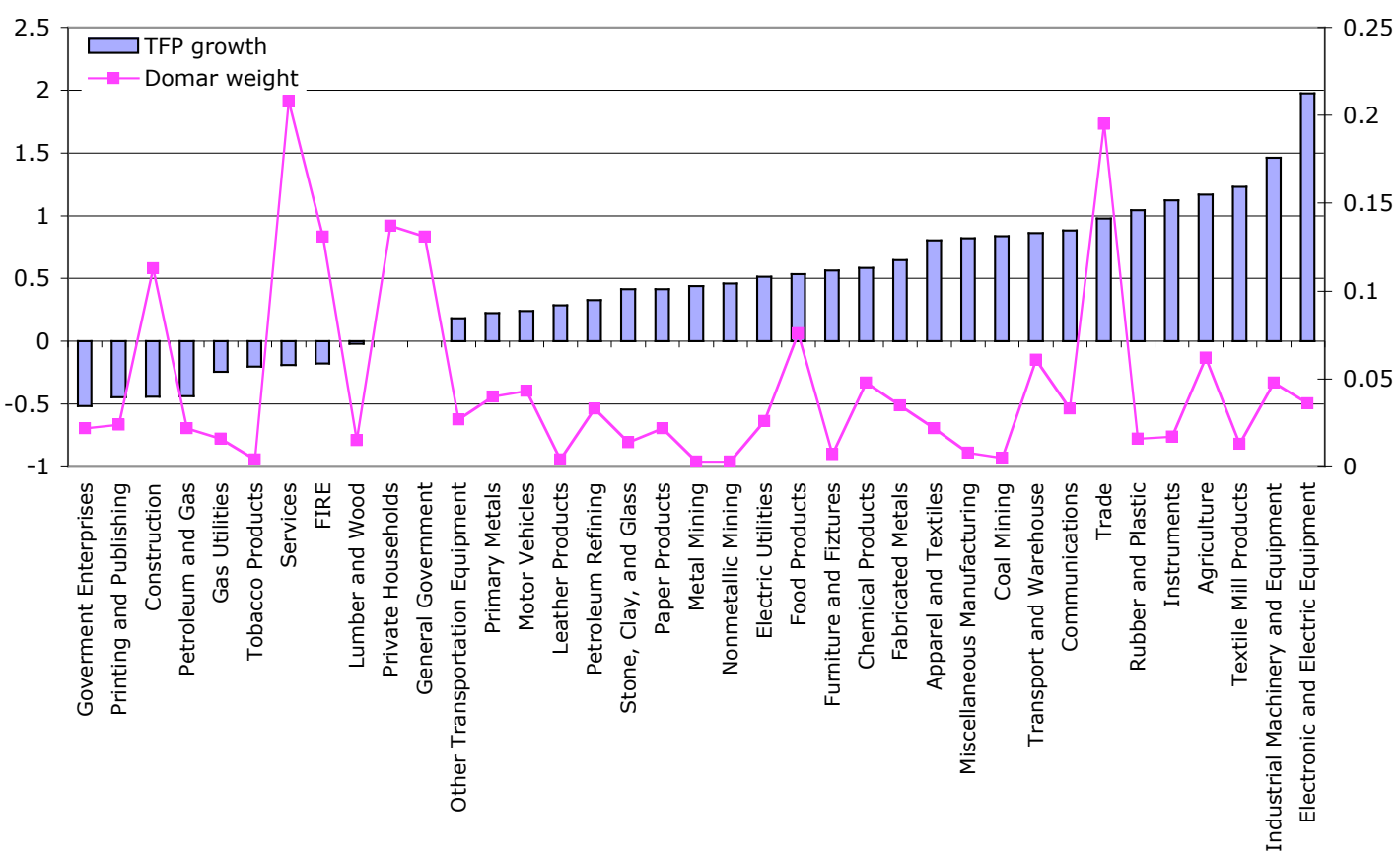

Sources: See Table 10. 


\section{Figure 11}

Exports (Value) versus Labor Productivity (Value Added per Worker), U.S. Industries, 1970/80/90, 2/3/4-digit SIC Classifications
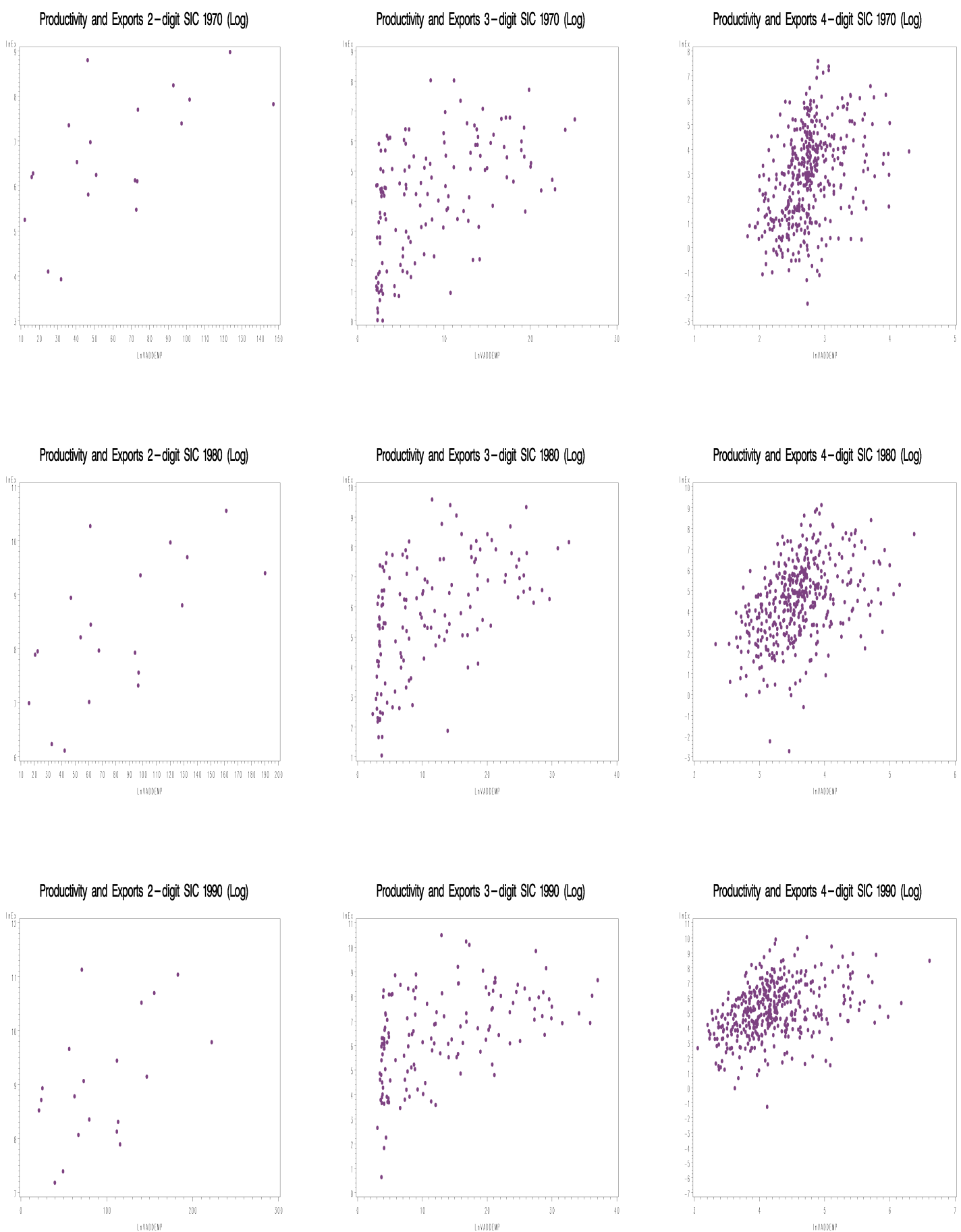

Sources: Value added per worker from "Manufacturing Industry Productivity Database" (Bartelsman, Becker, and Gray); exports from "U.S. Trade by 1972-SIC Category, 1958-1994" (Feenstra). Both databases at http://www.nber.org/data/. 